\title{
The elaboration and empirical evaluation of the De Goede learning potential structural model
}

\author{
S. Van Heerden and C. Theron* \\ Department of Industrial Psychology, University of Stellenbosch, Private Bag X1, Matieland, 7602, Tel: 021-8083009 \\ *To whom all correspondence should be addressed \\ ccth@sun.ac.za
}

\begin{abstract}
As a direct result of having segregated amenities and public services during the Apartheid era where Black individuals were provided with services inferior to those of White individuals, the country is currently challenged by serious and a debilitating skills shortage across most industry sectors, high unemployment and poverty rates, and inequality in terms of income distribution as well as in terms of racial representation in the workforce. These challenges are the consequence of a larger problem that knowledge, skills and abilities are not uniformly distributed across all races. In the past, and still now, White South Africans had greater access to skills development and educational opportunities. It is this fundamental inequality that has to be addressed. It is argued that skills development - specifically affirmative action skills development should form part of the solution. A need therefore exists to identify the individuals who would gain maximum benefit from such affirmative action skills development opportunities and to create the conditions that would optimise learning performance. To achieve this, an understanding is required of the complex nomological network of latent variables that determine learning performance. De Goede (2007) proposed and tested a learning potential structural model based on the work of Taylor (1994). The primary objective of this study was to expand on De Goede's (2007) learning potential structural model in order to gain a deeper understanding of the complexity underlying learning performance. A subset of the hypothesised expanded learning potential structural model was empirically evaluated. The first analysis of the structural model failed to produce a good fit to the data. The model was subsequently modified by both adding additional paths and by removing insignificant paths. The final revised structural model was found to fit the data well. All paths contained in the final model were empirically corroborated. The practical implications of the learning potential structural model on HR and organisations are discussed. Suggestions for future research are made by indicating how the model can be further elaborated. The limitations of the study are also discussed.
\end{abstract}

\section{Introduction}

South Africa currently faces a number of serious challenges that include the shortage of critical skills in the marketplace, high unemployment and poverty, inequality in terms of income distribution and in the representation of various segments of the population in the workforce and other social challenges such as a high crime rate and an increasing dependence on social assistance grants. These challenges are complexly causally interconnected. Each of these challenges directly and/or indirectly influences the others and also has in common the factors that cause and exasperate them. A penetrating understanding of the need for urgent action lies in appreciating this complex interplay between the various challenges. Due to the nature of the fundamental cause of these problems the human resource management/industrial organisational psychology profession has an important role to play in advocating the need for urgent action and in finding intellectually honest solutions to these problems facing the country (Van Heerden, 2013).

South Africa is in a rather paradoxical position. On the one hand there is a high unemployment-and poverty rate with thousands of hopeful people desperately, and mostly unsuccessfully, looking for work, and on the other hand the marketplace has available many lucrative, well-paying jobs but for which organisations are unable to find suitably skilled individuals to fill the positions. This situation has the potential for perfect symbiosis. However, in the face of inaction, the current situation presents a volatile mixture that keeps South African society uncomfortably close to social anarchy. Moreover the risk of a South African spring will continue to increase as those suffering perceive little or no progress in alleviating the problem.

The concern exists that currently the government and the private sector are focusing too heavily on treating the problem symptoms instead of addressing the real root causes. Making lofty promises of job creation, poverty alleviation, building houses for deserving citizens and the payment of social grants can somehow be likened to treating a gunshot wound by putting a plaster on it. It is merely addressing the symptoms of a much larger problem that is being ignored. This larger problem is that knowledge, skills and abilities are not uniformly distributed across all races. The situation is that in the past, and still now, White South Africans have greater access to skills development and educational opportunities. It is this fundamental cause that must be addressed in order to create a sustainable solution to the challenges described above. Skills development specifically affirmative action skills development prevents itself as a means to overcome the challenges the country 
faces as a result of Apartheid. Lasting progress in the battle against poverty and its manifestations can only be achieved by means of providing education and skills development as to achieve the self-reliance that stems from employment opportunities and decent wages (Teffo, 2008; Woolard, \& Leibbrandt, 1999).

For affirmative action skills development programmes to lead to the desired outcomes, close collaboration will be required between the government and the private sector. Private sector cannot wait for government to salvage the situation on its own (Dinokeng Scenarios, undated). The purpose of an affirmative skills development opportunity is to impart skills onto individuals who have no or only very limited skills but who has the potential to develop the more advanced skills. The pool of available candidates to recruit from consists of millions of individuals all with highly underdeveloped skills, knowledge, and abilities. The concern exists that recruiting for a skills development opportunity currently is little more than a process of randomly sheparding desperately unemployed individuals into a learnership programme. Although government has placed a strong emphasis on skills development and is taking steps to further the cause, concerns exist regarding the learners who actually participate in the skills development opportunities. A review of media reports (Freeman, 2005; Letsoalo, 2007a; Letsoalo, 2007b; Ncana, 2010; Stokes, 2009) generally reveal that skills development is hampered by challenges such as a mismatch between learner expectations and the actual learnership programme, high absenteeism and turnover among learners, a high dismissal rate of learners, learners displaying poor attitudes and a lack of respect, and learners having a sense of entitlement leading to a poor work ethic. In 2007 the Department of Labour's implementation report on skills development stated that almost $80 \%$ of learners registered for SETA learnerships did not complete their training (Letsoalo, 2007a; Letsoalo, 2007b). Others (Alexander, 2006) give examples of skills development programmes where up to $90 \%$ of learners did not complete their training.

Organisations invest in skills development interventions as an investment in future skills. It is therefore essential to ensure maximum return on investments made in affirmative development ${ }^{1}$. To achieve maximum return on its affirmative development investment organisations must be able to select from the enormous pool of affirmative action candidates, the candidates who are the best match for the programme and the organisation, who will complete the programme, and then be suitable to be permanently employed in the organisation. In order to identify the individuals who would gain maximum benefit from such development opportunities, a valid selection procedure is required. To determine the predictors that should be included in an affirmative development selection battery, an understanding is required of the factors that determine whether or not a learner will be successful if entered into a

\footnotetext{
${ }^{1}$ This argument in essence, however, also applies to not-for-profit organisations. These organisations also bear the responsibility to ensure maximum returns on their limit resources that are invested.
}

development opportunity. Other person-centered characteristics and situational characteristics not necessarily predisposed to control via selection, however, also affect learning performance. Effective selection is therefore not sufficient to ensure that all the candidates in the affirmative action intervention will achieve success. HR's attempts at ensuring successful affirmative development should therefore extend beyond selection. The nature and content of these additional HR interventions, however, also have to be informed by the identity of the specific latent variables that determine learning performance and the manner in which they combine to determine the level of performance that is achieved by specific learners.

De Goede (2007) conducted research based on the work of Taylor $(1989,1992,1994,1997)$ on the concept of learning potential. De Goede sought to explicate the structural model underlying the APIL-B test battery to uncover the nomological network of variables that collectively constitute the learning potential construct according to the APIL-B test battery. Based upon Taylor's definition of learning potential, the study conducted by De Goede (2007) included only cognitive ability variables. It however seems highly unlikely that cognitive ability would be the only attribute that influences success at a learning task. The nomological network of variables underpinning the construct of learning potential is vast and most likely consists of a multitude of richly structurally interwoven variables that affect success at learning. In this vast and rich structure, many other person characteristics (along with situational characteristics), in addition to cognitive ability, determine the extent to which learning takes place.

\section{Research objectives}

The objectives of this study consequently are to expand and/or modify the learning potential structural model proposed by De Goede (2007) by identifying additional learning competencies and additional learning competency potential latent variables neglected by the De Goede (2007) model, explicate the nature of the causal relationships existing between learning competency potential latent variables, learning competencies and outcomes and to empirically test the proposed elaborated structural model.

\section{Developing the expanded Van Heerden - De Goede learning potential structural model}

De Goede (2007), relying on the work of Taylor (1989, 1992, 1994, 1997), argued that differences in learning performance between individuals can be explained in terms of four constructs, namely: abstract reasoning capacity, information processing capacity (speed, accuracy, and flexibility), transfer of knowledge and automatisation. These four constructs in collaboration were used to explain how differences in intellectual ability account for differences in learning performance. Based upon Taylor's theoretical position and his conceptualisation of the structural interplay between these constructs, De Goede (2007) proposed a structural model that depicts the hypothesised causal 
linkages between the constructs that constitute learning potential. According to the model, an individual's capacity to transfer knowledge is causally determined by the individual's abstract reasoning capacity. Also, that an individual's ability to automate is causally determined by the individual's capacity to process information. Furthermore, that transfer of knowledge and automatisation are causally linked to learning performance ${ }^{2}$. Reasonable fit was obtained for the proposed a structural model but only limited support was obtained for the proposed causal paths. Support was found for only four of the ten path hypotheses (De Goede, 2007).

In order to achieve the desired goal of developing an expanded model of learning potential that is comprehensive, theoretically justifiable and closely approximates reality, both cognitive and non-cognitive factors should be included in the model. Due to the persuasive nature of the theoretical arguments underpinning the De Goede (2007) model and specific methodological flaws in the De Goede study (De Goede \& Theron, 2010) all the original causal paths hypothesised by De Goede (2007) are retained in the proposed expanded Van Heerden - De Goede learning potential structural model despite the failure of the original study to corroborate many of the proposed paths.

H1: In the proposed Van Heerden - De Goede learning potential structural model it is hypothesised that information processing capacity positively influences automatisation, that automatisation mediates the impact of information processing capacity on transfer of knowledge, that abstract reasoning ability positively influences transfer of knowledge, and that transfer of knowledge and automatisation positively influences learning performance during evaluation

It seems unlikely that non-cognitive factors will affect the learning competencies transfer and automatisation directly. The key to the elaboration of the De Goede (2007) learning potential structural model therefore lies in the identification of additional learning competencies that also constitute learning along with transfer and automatisation. A central premise of the argument presented here is that learning behaviourally involves more than transfer and automatisation.

\section{Additional learning competencies}

\section{Time cognitively engaged}

The amount of time that a student spends on learning tasks is frequently cited in the literature to be an important variable affecting academic success (Gettinger \& Seibert, 2006; Nonis \& Hudson, 2006; Singh, Granville \& Dika,

\footnotetext{
2 De Goede (2007) and De Goede and Theron (2010) did not distinguish between learning performance in the classroom and learning performance during evaluation. It will, however subsequently be argued that this is a vitally important distinction to make in the elaborated Van Heerden-De Goede leering potential structural model.
}

2002). In any training or instructional environment it is important to recognise that increasing the amount of time on learning tasks on its own does not lead to substantial achievement gains, the amount of engaged time must also be maximised. Although the amount of time teachers allocate (allocated time) and use for instruction (instructional time), as well as the proportion of time during which students are engaged (engagement rate), are all positively correlated with learning, it is the proportion of engaged time that is productive, active and successful that relates most strongly to learning performance (Nonis \& Hudson, 2006). Cognitive indices of engagement include cognitive strategy use, attention, task mastery, and preference for challenging tasks (Chapman, 2003; Davis, Chang, Andrzejewski \& Poirier, 2010). According to Zhu, Chen, Ennis, Sun, Hopple, Bonello, Bae and Kim (2009) and Chapman (2003), cognitive engagement refers to the extent to which students are attending to and expending mental effort in the learning tasks encountered. Students' cognitive engagement represents the intentional and purposeful processing of lesson content. It is widely found in the literature (Appleton et al., 2006; Bayat \& Tarmizi, 2010; Davis et al., 2010; Greene \& Miller, 1996; Metallidou \& Vlachou, 2007; Rastegar, Jahromi, Haghigli \& Akbari, 2010; Ravindran, Greene \& DeBacker, 2005) that cognitive engagement can be conceptualised as a bipolar construct where a cognitively engaged student will employ deep processing during the learning process whereas a student who is not cognitively engaged will merely employ surface processing during learning. This conceptualisation is based on the influential "levels of processing," (Craik \& Lockhart, 1972) and subsequent "elaborative processing"' (Anderson \& Reder, 1979) theories. These theories posit that the quality of our learning, our understanding, depends on the level of our cognitive engagement.

Cognitive engagement as constitutively defined in this study is a learning competency that partially constitutes learning performance in the classroom. As such, cognitive engagement, or deep processing, plays an important role in students' academic learning performance during evaluation. It is suggested that the use of different types of processing result in different learning outcomes, and, thus, different levels of achievement. It has generally been found that deep processing is typically regarded to be more adaptive as it that brings students to better insight in the learning material and therefore higher achievement outcomes, whereas surface processing is considered to be a less desirable form of the learning process that leads to a poorer understanding of the learning material and therefore lower level of academic performance (Greene \& Miller, 1996; Liem, Lau \& Nie, 2008; Ravindran et al., 2005; Richardson \& Newby, 2006; Sins, Van Joolingen, Savelsbergh, \& van HoutWolters, 2008). The constructs time on learning tasks and cognitive engagement, are for the purpose of this study combined and conceptualised as a single construct, namely time cognitively engaged. Time cognitively engaged, as defined here, involves the extent to which individuals are spending time attending to and expending mental effort in their learning tasks encountered. The mental effort the learner exerts, as well as for how long that individual exerts 
that mental effort, is therefore vital in its combination. In the expanded Van Heerden - De Goede learning potential structural model transfer is hypothesised to mediate the effect of time cognitively engaged on learning performance during evaluation. It is therefore hypothesised that in order for transfer to occur, the student must be expending mental effort and utilising cognitive strategies to promote transfer. However, as was stated previously, it is not only the quality of mental effort that is important but also the length of time for which the student exerts that effort. The combination of mental effort and time spent encapsulates the construct of time cognitively engaged.

H2: In the proposed learning potential structural model it is hypothesised that time cognitively engaged positively influences transfer

\section{Metacognitive regulation}

In addition to the significant impact that time cognitively engaged may have on learning, numerous studies (Appleton et al., 2006; Bayat \& Tarmizi, 2010; Davis et al., 2010; Greene \& Miller, 1996; Metallidou \& Vlachou, 2007; Rastegar et al., 2010; Ravindran et al., 2005) state the importance of regulating student cognition during learning. Not only is it important for a student to be cognitively engaged, but is also necessary for the student to plan, organise, regulate and monitor cognitive resources for increased efficiency during learning. This latter concept refers to the process of meta-cognitive regulation. Flavell (1976) was the first to identify the phenomenon called metacognition. According to Flavell (1976) meta-cognition refers to one's knowledge concerning one's own cognitive processes or anything related to them. More simply, metacognition can be described as cognition about cognition, or thinking about thinking (Boström \& Lassen, 2006; Efklides, 2006; Georghiades, 2004; Mitchell, Smith, Gustafsson, Davidsson \& Mitchell, 2005). Subsequent to Flavell's initial conceptualisation, many authors have undertaken to expand upon the understanding of the construct. Schraw and Dennison (1994) describe meta-cognition as the ability to reflect upon, understand, and control one's learning while Tobias and Everson (1996) describe meta-cognition as the ability to monitor, evaluate, and make plans for one's learning. Meta-cognition is usually related to learners' knowledge, awareness and control of the processes by which they learn and the meta-cognitive learner is thought to be characterised by ability to recognise, evaluate and, where needed, reconstruct existing ideas (Georghiades, 2004). Literature on meta-cognition propose that it is a multidimensional construct and differentiates between two major components, namely meta-cognitive knowledge and meta-cognitive regulation (Kuhn, 2000; Schraw, 1998; Schraw \& Dennison, 1994; Schwartz \& Perfect, 2002). Meta-cognition thus includes both an awareness of cognition and the capacity to change cognitions.

According to Schraw and Dennison (1994) and Schraw (1998), meta-cognitive regulation refers to the processes that facilitate the control aspect of learning. In other words, meta-cognitive regulation refers to a set of activities that help students control their learning. According to Schmidt and Ford (2003), meta-cognitive regulation include decisions such as where to allocate one's resources, the specific steps to be used to complete the task, the speed and intensity at which to work on the task, and the prioritisation of activities. Meta-cognitive regulation thereby constitutes a fourth learning competency (along with transfer, automisation and time cognitively engaged). A number of regulatory skills are described in the literature. This theoretical argument is based upon the work of Schraw (1998) who described the regulatory skills of (a) planning, (b) monitoring, and (c) evaluating. Schraw (1998) postulates meta-cognition to be domain-general in nature, rather than domain-specific. Veenman, Elshout and Meijer (1997), Veenman and Verheij (2003) and Veenman, Wilhelm and Beishuizen (2004) obtained strong support for the generality of meta-cognitive skills. The above domain-generality of meta-cognitive regulation may have powerful implications in the domain of learning potential. Empowering affirmative development candidates with meta-cognitive skills may give them the tools to not only gain skills in the subject matter of the specific learning intervention, but will equip them with the means to allow learning across subject areas and domains.

Meta-cognitive regulation as constitutively defined in this study is a learning competency that constitutes learning performance in the classroom. Meta-cognitive regulation is the second additional learning competency to be added to the proposed expanded learning potential structural model. It is however, hypothesised that meta-cognitive regulation will not directly influence learning performance during evaluation but that it will rather do so through the mediating effects of transfer. Therefore, in the proposed expanded learning potential structural model it is hypothesised that meta-cognitive regulation positively affects transfer.

\section{H3: In the proposed learning potential structural model it is hypothesised that meta-cognitive regulation positively influences transfer.}

According to Gettinger and Seibert (2006), time cognitively engaged is related to meta-cognition. According to Gettinger and Seibert, cognitive engagement requires some degree of self-regulation of learning. Specifically, a strategy for increasing engaged learning time would include a focus on how to develop student meta-cognitive skills. This will enable students to regulate their own cognitively engaged time effectively. This will include: (a) providing students with knowledge about strategies to promote cognitive engagement during learning tasks and how to use them, (b) demonstrating how and when utilisation of strategies is appropriate for maximising the efficiency of learning time, (c) providing feedback on the appropriate use of strategies, and (d) providing instruction concerning when and why strategies should be used and how strategy use can enhance their learning time. The relationship between time cognitively engaged and meta-cognition is supported by Metallidou and Vlachou (2007) who state that the use of "deep," meaningful processing strategies in conjunction 
with the use of meta-cognitive strategies lead to better performance and enhanced learning performance. Landine and Stewart (1998) also support the relationship between time cognitively engaged and meta-cognitive regulation. According to Landine and Stewart, deep processing strategies are considered to involve high level uses of metacognition while the surface approach involves a shallow use of meta-cognition.

H4: In the proposed learning potential structural model it is hypothesised that meta-cognitive regulation positively influences time cognitively engaged.

\section{Additional learning competency potential latent variables}

The level of competence that learners achieve on the learning competencies is not a random event. Whether or not learners will display the behaviours required to achieve the desired learning outcomes depends on the presence or absence of certain person-centered characteristics and on specific variables characterising the learning situation. The research objective requires the identification of additional learning competency potential latent variables, other than information processing capacity and abstract thinking capacity that affect learning performance during evaluation through the four identified competencies comprising classroom learning performance.

\section{Metacognitive-knowledge}

According to Veenman, Van Hout-Wolters and Afflerbach (2006), meta-cognitive knowledge refers to explicit knowledge of one's cognitive strengths and weaknesses. Similarly, Sperling, Howard, and Staley (2004) refer to meta-cognitive knowledge as how much an individual understands about the way they learn. Schraw (1998) refers to meta-cognitive knowledge as what individuals know about their own cognition or about cognition in general. Research suggests that meta-cognitive knowledge and metacognitive regulation are related to each other (Schraw, 1998) and that meta-cognitive knowledge is a prerequisite for meta-cognitive regulation (Baker, 1989). Support for this stance lies in the argument that if students cannot distinguish between what they know and do not know, they can hardly be expected to exercise control over their learning activities or to select appropriate strategies to progress in their learning (Schmidt \& Ford, 2003). Research results from Sperling et al. (2004) support the hypothesis that metacognitive knowledge precedes meta-cognitive regulation. Sperling et al. (2004) conducted two studies examining the relationship between the meta-cognitive knowledge and meta-cognitive regulation, and reported strong correlations in both studies $(\mathrm{r}=, 75, \mathrm{p}<, 001 ; \mathrm{r}=, 68, \mathrm{p}<, 001)$.

H5: In the proposed learning potential structural model it is hypothesised that meta-cognitive knowledge positively influences meta-cognitive regulation.

\section{Learning motivation}

According to Ames and Archer (1988), learning motivation is characterised by long-term, quality involvement in learning and commitment to the process of learning. It is the desire or want that energises and directs goal-oriented learning behavior. According to Brewster and Fager (2000) learning motivation refers to a student's willingness, need, desire and compulsion to participate in, and be successful in, the learning process. Colquitt and Simmering (1998) has defined learning motivation as the desire on the part of trainees to learn the content of the training programme. Motivation influences direction of attentional effort, the proportion of total attentional effort directed at a task and the extent to which attentional effort toward the task is maintained over time. Learning motivation determines the extent to which an individual directs his or her energy towards the learning task in an attempt to form structure and ultimately to transfer existing knowledge to the current task. Previous research (Greene, Miller, Crowson, Duke \& Akey, 2004; Krapp, 1999; Pintrich \& Schrauben, 1992; Singh et al., 2002) more specifically suggests a relationship between learning motivation and time cognitively engaged. In terms of this argument learning motivation affects engagement in academic tasks, and engagement in academic tasks subsequently facilitates transfer.

H6: In the proposed learning potential structural model it is hypothesised that learning motivation positively influences time cognitively engaged

Landine and Stewart (1998) suggested a positive relationship between the use of meta-cognition and learning motivation in students. Furthermore, Krapp (1999) reported learning motivation to be a determinant of the use of metacognitive strategies. The position that learning motivation is a determinant of meta-cognitive regulation is in accordance with the hypothesis of Schmitt and Sha (2009). Schmitt and Sha argued that meta-cognitive knowledge is a prerequisite for meta-cognitive regulation, however, they believe that although meta-cognitive knowledge may enhance one's selfcontrol of cognition when the knowledge is being implemented, such knowledge does not guarantee the control of cognition. Schmitt and Sha (2009) believed that external variables such as a lack of learning motivation may influence whether or not a learner will apply their metacognitive knowledge. This line of reasoning posits that students with higher levels of learning motivation are more likely to make use of meta-cognitive strategies and be successful at learning. ${ }^{3}$

H7: In the proposed learning potential structural model it is hypothesised that learning motivation positively influences meta-cognitive regulation

\section{Goal-orientation}

Learning goal-orientation has of late been receiving increased attention in the literature for the positive effect it

\footnotetext{
3 The question should, moreover, be raised whether a learning motivation $\mathrm{x}$ meta-cognitive knowledge interaction effect should not also be hypothesised.
} 
has on learning performance (Ames \& Archer, 1988; Bell \& Kozlowski, 2002; Bulus, 2011; Chiaburu \& Marinova, 2005; Day, Yeo \& Radosevich, 2003; Dweck \& Leggett, 1988; Farr, Hofmann \& Ringenbach, 1993; Kozlowski, Gully, Brown, Salas, Smith \& Nason, 2001; Salas \& Cannon-Bowers, 2001; Locke, 1996; Schmidt \& Ford, 2003; Van Hooft \& Noordzij, 2009). A definition of goalorientation is provided by Chiaburu and Marinova (2005) and Payne, Youngcourt and Beaubien (2007), who refer to goal-orientation as an individual's dispositional goal preferences in achievement situations. According to Bulus (2011) goal-orientation theory proposes that students' level of motivation and behaviours can be understood by considering the reasons learners offer to justify the effort they extend in academic work or the purpose of doing their academic work. For the purpose of this study goalorientation is conceptualised as a two-dimensional construct distinguishing between learning goal-orientation ( $L G O)$, whereby individuals seek to develop competence by acquiring new skills and mastering novel situations, and performance goal-orientation $(P G O)^{4}$, whereby individuals pursue assurances of their own competence by seeking good performance evaluations and avoiding negative ones (Ames \& Archer, 1988; Bell \& Kozlowski, 2002; Dweck \& Leggett, 1988; Salas \& Cannon-Bowers, 2001; Schmidt \& Ford, 2003). According to Kozlowski et al. (2001) the originators of goal-orientation postulated that $L G O$ and $P G O$ are mutually exclusive, in other words, goalorientation was conceptualised as a single bipolar trait. Button, Mathieu and Zajac (1996), however, contend that learning goals and performance goals are not mutually exclusive. Rather, $L G O$ and $P G O$ are viewed as separate traits and it is therefore possible for an individual to simultaneously strive to improve his/her skills and to perform well relative to others. The latter position is assumed in this study.

A learner that favours a $L G O$ believes that success requires interest, effort, and collaboration and views effort positively because it is perceived as a means toward accomplishment. According to Ames and Archer (1988), with a $L G O$ the process of learning itself is valued, and the attainment of mastery is seen as dependent on effort. When performance on a task is poor or when facing failure, the individual will not offer personal attributions for their failure. Rather than viewing setback and difficulties as failures, they will view it as challenges to be mastered through effort. Poor performance and failure causes them to increase effort and persistence or to analyse and change their strategies. $L G O$ individuals are likely to choose difficult and challenging tasks, as this will allow them to exert effort and

\footnotetext{
4 It has subsequently been argued that $P G O$ is in fact multidimensional and that goal-orientation should rather be considered a three-dimensional construct rather than a twodimensional construct. Considering that $P G O$ is defined as the desire to gain favourable judgments and avoid unfavourable judgments about one's ability, vandeWalle (1997) suggested that $P G O$ should be partitioned into two dimensions which he labeled: prove performance goal-orientation and avoid performance goalorientation.
}

subsequently enable them to develop their competencies (Ford et al, 1998). According to Kozlowski et al. (2001) a $L G O$ is viewed as an adaptive response to novel or challenging achievement situations. Individuals with a $L G O$ are thought to be attracted to such situations and approach them with an orientation toward self-improvement. They are resilient to challenge, persisting in the face of obstacles and failures. Furthermore, the two goal-orientations differ in terms of the standard used for evaluating and defining performance. Whereas individuals with a strong $L G O$ evaluate their competence according to whether they have mastered the task or developed their skills (i.e., an absolute or intrapersonal standard), individuals with a strong $P G O$ evaluate their competence according to how they performed compared to others (i.e., a normative standard) (Ford et al., 1998). Therefore, $L G O$ and $P G O$ represent different ideas of success.

It seems unlikely that a $L G O$ will have a direct effect on transfer and automisation as these two competencies are largely dependent on the cognitive ability of the learner. It can, however, be argued that since learners high on $L G O$ tend to believe that crystalised intelligence and performance can be improved through increased effort and focus it follows that LGO should have an impact on time cognitively engaged and on meta-cognitive regulation. Accumulating evidence has established a consistent pattern that a $L G O$ would facilitate time cognitively engaged (Ames \& Archer, 1988; Dupeyrat \& Marine, 2005; Dweck \& Legget, 1988; Greene \& Miller, 1996; Greene et al., 2004; Rastegar et al., 2010). Students who feel that mastering skills and increasing understanding and knowledge are important ( $L G O)$ engage more in deep processing. This relation makes sense as students with a $L G O$ attempt to gain rich insight in the given learning material and will therefore engage in deep cognitive processing to increase their comprehension (Sins et al., 2007).

Research conducted by Schmidt and Ford (2003), found that a $L G O$ was positively related to meta-cognition. Individuals with a greater focus on learning the training content reported that they more actively monitored their learning processes. Similarly, Ford et al. (1998) conducted a study and found a relationship between $L G O$ and meta-cognitive regulation. Individuals with a $L G O$ engaged in greater meta-cognitive activity during learning. Individuals who approached learning environment with the purpose of learning were more active in attending to and correcting their understanding of the task. McWhaw and Abrami (2001) also found that individuals who are more learning oriented employ meta-cognitive regulation more often than students who are more performance oriented.

According to Ames and Archer (1988), students with a $L G O$ are motivated by the desire to learn something new. They are not concerned with how long it takes or how many mistakes they have to make to learn. It is the drive to develop competence by acquiring new skills and mastering novel situations. A LGO therefore energises an individual to pursue behaviour that will enhance learning and subsequently motivates the individual to learn. Research by 
Colquitt and Simmering (1998) found a positive relationship between $L G O$ and learning motivation. Learners who had high levels of this personality variable exhibited higher learning motivation levels during the learning process. According to Baird, Scott, Dearing and Hamill (2009), learners who pursue learning goals rather than performance goals are more likely to show optimal motivation for academic tasks. It is therefore posited that a $L G O$ positively influence the competency variables time cognitively engaged and meta-cognitive regulation. However, $L G O$ will not directly influence time cognitively engaged and metacognitive regulation, but will do so through mediating the effect of learning motivation.

H8: In the proposed learning potential structural model it is hypothesised that a learning goal-orientation positively influences learning motivation.

\section{Conscientiousness}

Costa and McCrae (as cited in Nijhuis, Segers and Gijselaers, 2007) describes conscientiousness as the level of organisation, persistence and goal-directed behaviour of the individual. Individuals high in conscientiousness tend to be strong-willed, responsible, neat and well organised. Conscientious persons are characterised as being industrious, systematic, dutiful, high on achievement striving, and hardworking (Nijhuis et al., 2007). According to Eilam, Zeidner and Aharon, (2009), this dimension includes features such as ambition, energy, control of inclinations, diligence, carefulness, and being practical. This dimension is also termed 'the will to succeed,' which expresses orientation and intentional goal driven behaviour. Individuals scoring low in conscientiousness tend to be lazy, without orientation to succeed, and unable to meet their own standards as a results of deficient self-discipline. Conscientiousness involves a tendency to be organised, efficient, systematic, and achievement oriented. In the context of training, a conscientious personality may serve a trainee well in planning, forecasting, seeking out additional learning assistance, and following through with academic goals (Dean, Conte \& Blankenhorn, 2006).

Numerous studies have shown the importance of conscientiousness during learning (Barrick \& Mount, 1991; 2005; Bidjerano \& Dai, 2007; Colquitt \& Simmering, 1998; Furnham, Monsen \& Ahmetoglu, 2009; McCrae \& Costa, 1999; Nijhuis et al., 2007; O’Connor \& Paunonen, 2007; Steinmayr, Bipp \& Spinath, 2011; Eilam et al., 2009). Specifically researchers have found a positive relationship between conscientiousness and time cognitively engaged (Bidjerano \& Dai, 2007; McCrae \& Costa, 1999; McKenzie, Gow \& Schweitzer, 2004; Woo, Harms \& Kuncel, 2007). McKenzie et al. (2004) found in their research that conscientiousness was the most important predictor of learning strategy use, accounting for $15,2 \%$ of the variance. Students who displayed high levels of conscientiousness were more likely to report that they utilised learning strategies than students with a more lackadaisical nature. Bidjerano and Dai (2007) found that high conscientiousness is related to higher tendencies for the use of time management and effort regulation and higher order cognitive skills such as elaboration, critical thinking, and meta-cognition. The intrinsic connectedness of conscientiousness and time and effort regulation is expected because the construct of conscientiousness is expressed by attributes such as self-discipline, deliberation, hard-working attitude, order, dutifulness, compliance, and imperturbability. Following the above, a direct relationship is hypothesised between conscientiousness and time cognitively engaged.

H9: In the proposed learning potential structural model it is hypothesised that conscientiousness positively influences time cognitively engaged

A clear relationship between conscientiousness and metacognitive regulation has seemingly not yet been established as very limited research studies have been undertaken examining this relationship. However, Turban, Stevens and Lee (2009) allude to a positive relationship between conscientiousness and the use of meta-cognitive regulation. The lack of studies examining this relationship does not necessarily mean such a relationship does not exist, it merely indicates to the necessity of further theorising and empirical studies examining this relationship.

This study will follow the above line of thought and postulates that there is a positive relationship between conscientiousness and meta-cognitive regulation. However, the effect of conscientiousness on meta-cognitive regulation is probably not direct and it is rather postulated that the underlying causal dynamics operate via learning motivation. ${ }^{5}$ According to Barrick and Mount (1991; 2005), motivation is the major mediating link between personality and performance. Kanfer (1991) similarly advocated using a distal-proximal framework for examining personality effects and casts conscientiousness as a distal variable that influenced learning through the more proximal mechanism of learning motivation. Other studies have found evidence to support the proposed positive relationship between conscientiousness and learning motivation. Research by Colquitt and Simmering (1998) found a positive relationship between conscientiousness and learning motivation. Learners who had high levels of this personality variable exhibited higher learning motivation levels during the learning process. According to Colquitt and Simmering (1998), individuals who were reliable, self-disciplined, and persevering were more likely to perceive a link between effort and performance (i.e., expectancy) and were more likely to value high performance levels (i.e., valence). The above posits a strong argument of the positive relationship between personality, specifically conscientiousness, and learning motivation and is therefore included in the structural model.

\footnotetext{
${ }^{5}$ It is thereby also implied that that the effect of conscientiousness on time cognitively engaged is partially mediated by learning motivation.
} 
H10: In the proposed learning potential structural model it is hypothesised that conscientiousness positively influences learning motivation. Academic self-efficacy

Academic self-efficacy earned inclusion in the elaborated Van Heerden-De Goede learning potential structural model due to its prominence in the literature relating to training and learning and the strong evidence linking academic selfefficacy to classroom learning performance and to learning performance during evaluation (Bandura, Barbaranelli, Caprara \& Pastorelli, 1996; Ford et al., 1998; Hsieh, Sullivan \& Guerra., 2007; Schunk, 1990; Sedaghat et al., 2011; Skinner et al., 2008; Zimmerman, 2000), time cognitively engaged (Dupeyrat \& Marine, 2005; Greene \& Miller, 1996; Greene et al., 2004; Hsieh et al., 2007; McWhaw \& Abrami, 2001; Metallidou \& Vlachou, 2007; Schunk, 1990; Sins et al., 2008) and meta-cognitive regulation (Ford et al., 1998; Hsieh et al., 2007; Landine \& Stewart, 1998; Schmidt \& Ford, 2003).

Bandura (1977; 1997) defined perceived self-efficacy as personal judgments of one's capabilities to organise and execute courses of action to successfully complete tasks and attain designated goals. Judge and Bono (2001) described self-efficacy as one's estimate of one's fundamental ability to cope, perform, and be successful while Hsieh et al. (2007) describes self-efficacy as an individuals' belief about their capabilities to successfully complete a task. Self-efficacy is however more than merely telling ourselves that we can succeed. Self-efficacy involves a strong conviction of competence that is based on our evaluation of various sources of information about our efficacy. According to the theory of perceived self-efficacy, whether a person undertakes a task depends, in part, on his or her perceived levels of efficacy regarding that task. According to Bandura's (1997) key contentions in regards the role of selfefficacy beliefs in human functioning, "people's level of motivation, affective states, and actions are based more on what they believe than on what is objectively true" (p. 2). For this reason, how people (attempt to) behave can often be better predicted by the beliefs they hold about their capabilities than by what they are actually capable of accomplishing, for these self-efficacy perceptions help determine what individuals do with the knowledge and skills they have. Self-efficacy was originally conceptualised as task specific.

Bandura (1996; 1997) defined self-efficacy as an individual's perceptions of his/her ability to perform adequately in a given situation. However, despite Bandura's restrictive definition of the construct, generalised self-efficacy has merited some attention in the literature. Generalised selfefficacy is defined by Judge, Erez, Bono, and Thoreson (2002, p. 96) as a "judgement of how well one can perform across a variety of situations." According to this stance, generalised self-efficacy is therefore a motivational state because it involves the individual's beliefs regarding his/her abilities to perform and succeed at tasks across different situations (Kanfer \& Heggestad, 1997). Chen, Gully and
Eden (2001) have argued that generalised self-efficacy positively influences task specific self-efficacy across tasks and situations. Specifically, the tendency to feel efficacious across tasks and situations (i.e., generalised self-efficacy) "spills over" into specific situations. Chen et al. (2001) argue that disregard of generalised self-efficacy may exact a price in terms of theoretical comprehensiveness and proportion of variance explained in motivation research. In light of the compelling evidence given above in support of both generalised self-efficacy and task specific self-efficacy, this study will incorporate both constructs. Specifically, task specific self-efficacy will be defined as referring to academic self-efficacy (ie an individual's beliefs regarding his/her abilities to perform and succeed at tasks specific to learning and academic situations) and generalised self-efficacy will be defined as an individual's beliefs regarding his/her abilities to perform and succeed at tasks across different situations. Furthermore, it is postulated that generalised selfefficacy positively influences task specific self-efficacy, or in other words, academic self-efficacy.

H11: In the proposed learning potential structural model it is hypothesised that generalised self-efficacy positively influences academic self-efficacy

Although self-efficacy is traditionally understood as being specific to the individual, it can also have a collective influence over a group. Because individuals operate collectively as well as individually, self-efficacy is both a personal and a social construct. Collective systems develop a sense of collective efficacy - a group's shared belief in its capability to attain goals and accomplish desired tasks (Bandura et al., 1996). For example, schools develop collective beliefs about the capability of their students to learn, of their teachers to teach and otherwise enhance the lives of their students, and of their administrators and policymakers to create environments conducive to these tasks. This line of reasoning seems especially relevant in the context of affirmative development in the shadow of Apartheid. The concern exists that Apartheid relentlessly bombarded Black South Africans with the message that they "are children of a lesser God", inferior, incapable of the same accomplishments as White South Africans. This may likely have affected their generalised self-efficacy and thereby also probably their academic self-efficacy.

In the proposed learning potential structural model it is hypothesised that academic self-efficacy positively influences learning motivation as individuals who believe that they are capable of learning may be more motivated to learn. Bandura's theory of self-efficacy (Bandura, 1977, 1986, 1997) indicates that academic self-efficacy determines the learning motivation and academic achievement. According to the authors, self-efficacy has an influence on preparing action because self-related cognitions are a major ingredient in the motivation process. Bandura et al. (1996) concur that an individuals' perceptions of academic selfefficacy affects learning motivation. This has been demonstrated in many studies. According to Schunk (1990), academic self-efficacy beliefs influence academic motivation and achievement. According to Baird et al. 
(2009), levels of academic self-efficacy influence learning motivation.

\section{H12: In the proposed learning potential structural model it is hypothesised that academic self-efficacy positively influences learning motivation}

Literature posits that a relationship exists between goalorientation and self-efficacy. Various researchers have found a positive relationship between self-efficacy and a learning goal-orientation LGO (Greene \& Miller, 1996; Greene et al., 2004; Kozlowski et al., 2001; Rastegar et al. 2010; Schmidt \& Ford, 2003). In addition to evidencing a positive relationship between the constructs, researchers (Ames \& Archer, 1988; Phan, 2010; Sedaghat et al., 2011) have found a causal relationship where high levels of academic selfefficacy determine the adoption of a $L G O$. According to Baird et al. (2009), youth with high levels of academic selfefficacy were more likely than their peers with low levels of academic self-efficacy to endorse learning-oriented goals. Kanfer (1991) suggested that individuals who view their intelligence as fixed $(P G O)$ have lower levels of general self-efficacy than individuals who view their intelligence as malleable $(L G O)$. Furthermore, Schunk (1990) found that students with higher self-efficacy tend to participate more readily, work harder, pursue challenging goals and spend much effort toward fulfilling identified goals (thereby referring to learning goals). Previous research results therefore suggest that a relationship exists between academic self-efficacy and learning goal-orientation.

H13: In the proposed learning potential structural model it is hypothesised that academic self-efficacy positively influences learning goal-orientation.

\section{Locus of control}

The concept of locus of control was originally developed by Julian Rotter in the 1950's and has its foundation in social learning theory (Marks, 1998). Locus of control refers to the extent to which individuals believe that they can control events and behavioural results in their lives (Judge \& Bono, 2001) or the extent to which people believe that the rewards they receive in life can be controlled by their own personal actions (Wang, Bowling, \& Eschleman, 2010). Literature on locus of control differentiates between an internal locus of control and external locus of control as two opposite poles on a bipolar continuum. According to Judge and Bono (2001), individuals with an internal locus of control believe they can control a broad array of factors in their lives. Gibson, Ivancevich, Donnelly and Konopaske (2006) state that people with an internal locus of control believe that they are masters of their own fate and bear personal responsibility for what happens to them. Individuals with an internal locus of control believe that rewards are contingent upon their own efforts. According to Joo, Joung and Sim (2011) having an internal locus of control means attributing results to internal factors, such as one's own behaviour or effort. Conversely, individuals with an external locus of control, or externals, view themselves as helpless pawns of fate controlled by outside forces over which they have little, if any, influence (Gibson et al., 2006). Locus of control emphasises that an individual tries to explain the outcomes of his or her behaviour as being controlled internally or externally; as being directly determined by their own behaviour or as being beyond their control. Locus of control is therefore based on causal beliefs regarding behaviouroutcome expectations of the individual. Other perspectives on the interpretations of locus of control have, however, been postulated by various authors. In this study locus of control is conceptualised according to the stance of Levenson and Miller (1976). According to this multidimensional view, an individual can be considered as having either (a) an internal locus of control, (b) an external locus of control as influenced by powerful others or (c) an external locus of control as influenced by fate or chance. This conceptualisation was chosen due to the relevance of the differentiation between powerful others and fate or chance in the South African context. An individual believing that outcomes are determined by powerful others might legitimately believe so due to the prior control that was placed upon them during Apartheid and may do so irrespective of their beliefs in their own abilities. This is in contrast to an individual believing that outcomes are determined by fate or chance as this could be more indicative of a lack of belief in their own abilities.

Locus of control seems a very relevant construct to consider in a study on affirmative development in South Africa. Since the advent of democracy in South Africa in 1994 previously disadvantaged individuals are being told by political leaders that they are entitled to receive free housing, free access to services, free education including tertiary education, that jobs will be created, that the wealth will be shared among the poor. These messages create a feeling that material possessions and means will be provided deus ex machina by external forces and that the need for own effort and to work to receive it has been eliminated. Political leaders are instilling a sense of external locus of control into individuals, that they are not required to affect the outcomes of their lives but that external forces will improve their lives for them. This reinforces the message that Apartheid forcefully brought home to many disadvantaged individuals; that the socio-political system controls one's fate. If you were Black you were denied numerous privileges and there was very little you could do about it. This thereby further enforces the necessity of including this construct in the study of affirmative action skills development.

According to Landine and Stewart (1998) there appears to be a link between learning motivation and an internal locus of control. More specifically, intrinsic motivation has been linked to an internal locus of control. Colquitt, LePine and Noe (2000) found locus of control to be highly related to learning motivation and subsequent skill acquisition; with internals being more motivated. The positive relationship between internal locus of control and learning motivation makes theoretical sense. An individual with an internal locus of control believes that success in an academic setting is dependent on his/her own efforts and contributions. 
Therefore, knowing that success in learning is possible under the condition of his/her own efforts, the internal should likely be more motivated to expend effort and work hard due to the belief that it will lead to success in learning. This in contrast with an individual with an external locus of control; such an individual will believe that success is not dependent on the self or own efforts, but rather dependent on external forces. An external will therefore not be motivated to expend effort or work hard as there is no belief that this effort will lead to success at learning.

H14: In the proposed learning potential structural model it is hypothesised that internal locus of control positively influences learning motivation.

According to Ford et al. (1998), a $L G O$ is related to a belief that success follows from effort (internal locus of control). This stance is supported by Dweck and Leggett (1988) who also believe that internal locus of control is strongly related to a $L G O$. According to the results of research conducted by Dweck and Leggett, those who hold a strong $L G O$ are more likely to perceive personal control over outcomes or events, ie. have an internal locus of control. Bulus (2011) reports very relevant research results on the relationship between locus of control, goal-orientation and learning. According to Bulus (2011), a $L G O$ is positively related to locus of control $(\mathrm{r}=, 35 ; \mathrm{p}=, 01)$ and academic achievement $(\mathrm{r}=, 15 ; \mathrm{p}<, 05)$ and avoidance $P G O$ is negatively related to locus of control $(\mathrm{r}=-$ $, 21 ; \mathrm{p}<, 01)$ and academic achievement $(\mathrm{r}=-, 19 ; \mathrm{p}<, 01)$. A positive relationship was found between locus of control and academic achievement $(\mathrm{r}=, 14 ; \mathrm{p}<, 05)$. According to these results, it could be said that as the level of internal locus of control and LGO increase the level of academic achievement increases, as the level of avoidance $P G O$ increases the level of academic achievement decreases, as the level of internal locus of control increases the level of $L G O$ increases and finally as the level of locus of control decreases (as the level of external locus of control increases) the level of avoidance $P G O$ increases.

The relationship between $L G O$ and internal locus of control can be theoretically explained by the stance of Dweck and Leggett (1988). Dweck and Leggett noted that goalorientation and locus of control both deal with the question of whether one perceives oneself to have personal control over important elements in one's life. However, locus of control pertains to individuals' perceived control over rewards or outcomes, while goal-orientation involves perceptions of control over the basic attributes that influence these outcomes (e.g., one's level of competence). Dweck and Leggett argues that a learning goal-orientation (ie the perception that one has control over and can increase and develop competence), is a precursor to an internal locus of control (ie the perception that success is due to own effort and competence). Therefore, an individual who believes that he/she is able to control, improve and develop their own competence $(L G O)$ is more likely to believe that they can determine their own success (internal locus of control). Therefore it is hypothesised that $L G O$ positively affects internal locus of control.
H15: In the proposed learning potential structural model it is hypothesised that learning goal-orientation positively influences internal locus of control. Feedback loops

In addition to the above hypotheses discussed, this study also postulates the existence of feedback loops within the learning potential structural model. A feedback relationship is suggested between learning performance during evaluation and learning motivation whereby positive learning experiences can further increase learning motivation and negative learning experiences can decrease learning motivation. This stance is supported by Brewster and Fager (2000) who reports that unpleasant experiences in the classroom and negative learning experiences may result in the deterioration of student learning motivation. The above clearly elucidates a feedback relationship between learning performance and learning motivation where success during learning can positively influence learning motivation and negative performance during learning can detrimentally affect learning motivation.

H16: In the proposed learning potential structural model it is hypothesised that learning performance during evaluation positively influences learning motivation.

According to Bandura (1986, 1977) self-efficacy is affected by five primary sources: (a) learning experience, (b) vicarious experience, (c) imaginal experiences, (d) social persuasion, and (e) physiological states. The most influential source of self-efficacy beliefs is the interpreted result of one's previous performance, or learning experience. Individuals engage in tasks and activities, interpret the results of their actions, and use the interpretations to develop beliefs about their capability to engage in subsequent tasks or activities. Therefore when a student achieves a successful learning outcome, it is likely to enhance the student's selfefficacy. Conversely, if the student receives a negative learning outcome, it is likely to have a negative effect on the student's level of self-efficacy.

This feedback relationship between academic self-efficacy and learning performance during evaluation has been found is some studies. According to Colquitt and Simmering (1998) low performance decreases self-efficacy levels. Wang et al. (2008) stated that the result of negative behaviour over a long time will lead to the decline of learners' learning efficacy, alluding to the fact that poor learning performance during evaluation has the ability to decrease academic selfefficacy. According to Baird et al. (2009) past performance is a major determinant of self-efficacy implying that poor performance is likely to negatively affect self-efficacy while good performance is likely to positively affect self-efficacy. The above clearly elucidates a feedback relationship between learning performance and academic self-efficacy where success during learning can positively influence academic self-efficacy and negative performance during learning can detrimentally affect academic self-efficacy. 
Hypothesis 17: In the proposed learning potential structural model it is hypothesised that learning performance during evaluation positively influences academic self-efficacy.

The foregoing theoretical argument logically culminates in the learning potential structural model depicted in Figure 1.

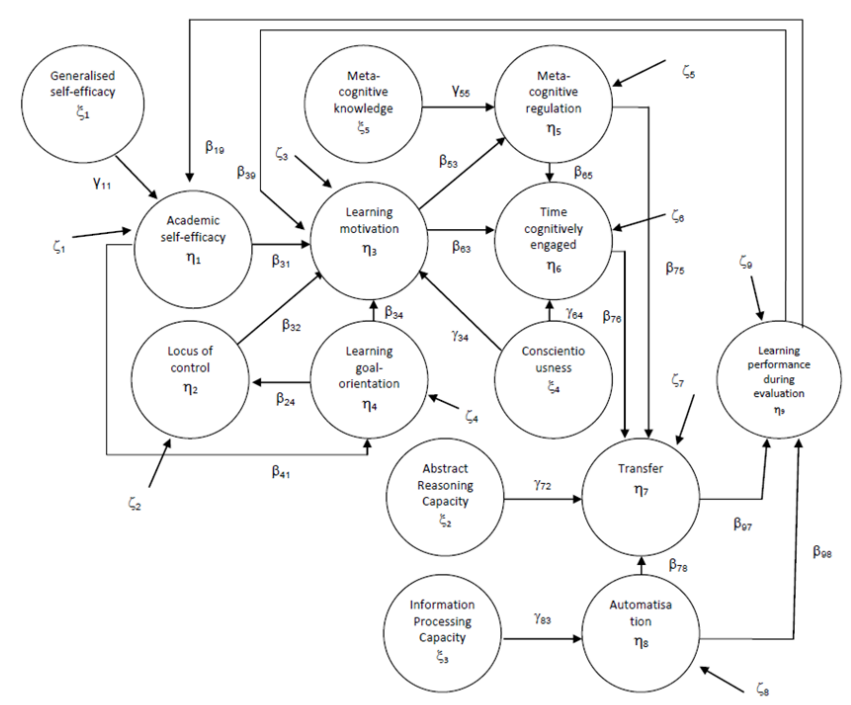

Figure 1: The hypothesised Van Heerden - De Goede expanded learning potential structural model

\section{Research methodology}

\section{Substantive research hypotheses}

Although learning performance in the classroom and learning performance during evaluation comprises essentially the same set of learning competencies the nature of the learning problem differs, the nature of the crystalised ability (or prior learning) that is transferred differs and the nature of the insight being automated differs. In the classroom specific crystalised ability developed through learning prior to the classroom instruction is transferred onto the novel learning problems comprising the curriculum. The meaningful structure that is found in the learning material in this manner is subsequently automated (Van Heerden, 2013). De Goede and Theron (2010) used the APIL subtests to measure transfer and automatisation as dimensions of learning performance in the classroom. The APIL purposefully uses essentially meaningless learning material to assess learning performance in a simulated learning opportunity so as to ensure that nobody is unfairly advantaged due to prior learning opportunities. These measures can, however, not be considered valid measures of the extent to which transfer and automatisation takes place in the classroom. Here prior learning does play a role. This seems to be an important oversight by De Goede and Theron (2010) because it is the actual transfer that takes place in the classroom and the subsequent automatisation of the derived insight that determines the learning performance during evaluation. Learning performance during evaluation involves transfer of the newly derived insight that has been written to a knowledge station in memory onto novel (learning) problems related to but qualitatively distinct from those encounter in the classroom. Learning performance during evaluation ought to be measured by confronting learners with novel learning problems that they should be able to solve by using the crystalised knowledge that they should have developed through transfer in the classroom (Van Heerden, 2013).

Operational measures of transfer and automatisation comprising learning performance in the classroom therefore have to be specific to the learning material relevant to the specific training or development procedure utilised in the empirical testing of the learning potential structural model and as dynamic measures they will have to be integrated into the training programme. Transfer and automisation as learning competencies have to be measured by observing these processes in action over time. That means that the extent to which learners solve/make sense of/find structure in novel learning problems that they are confronted with in class and how they use the solution to make sense of subsequent problems in class needs to be evaluated. How these insights are written to knowledge stations needs to be evaluated as well. That seems practically rather challenging. This line of reasoning points to the need to delete transfer and automatisation from the expanded model that is empirically tested as separate latent variables not because they do not belong there but because of the questionable utility of investing significant resources in overcoming the logistical challenges associated with the development and implementation of suitable measures of classroom transfer and automatisation but with virtually no subsequent practical value (in contrast to the generic APIL measure) (Van Heerden, 2013). Transfer and automatisation were consequently deleted from the expanded model that is empirically tested. Abstract reasoning capacity and information processing capacity as the direct determinants of transfer and automatisation were also deleted from the model. Furthermore, was also decided to not specifically test the hypothesis that generalised self-efficacy positively influences academic self-efficacy. Only academic selfefficacy was retained in the reduced structural model. This step was taken in an attempt to reduce that data collection burden resting on the researcher.

The reduced Van Heerden - De Goede learning potential structural model that was subjected to empirical testing is shown in Figure 2. Although the reduced Van Heerden - De Goede learning potential structural model no longer contains any of original the De Goede (2007) latent variables but for learning performance during evaluation, the study nonetheless remains an attempt to elaborate on the De Goede model. The model being subjected to test remains a subset of the model depicted in Figure 1. If the reduced model will be modified based on empirical feedback obtained in this study, the modified model will be grafted back into the larger model. The larger research project of which this study forms part will in due course subject the additional as yet untested hypotheses that emerged from the theorising in this study to empirical test. 


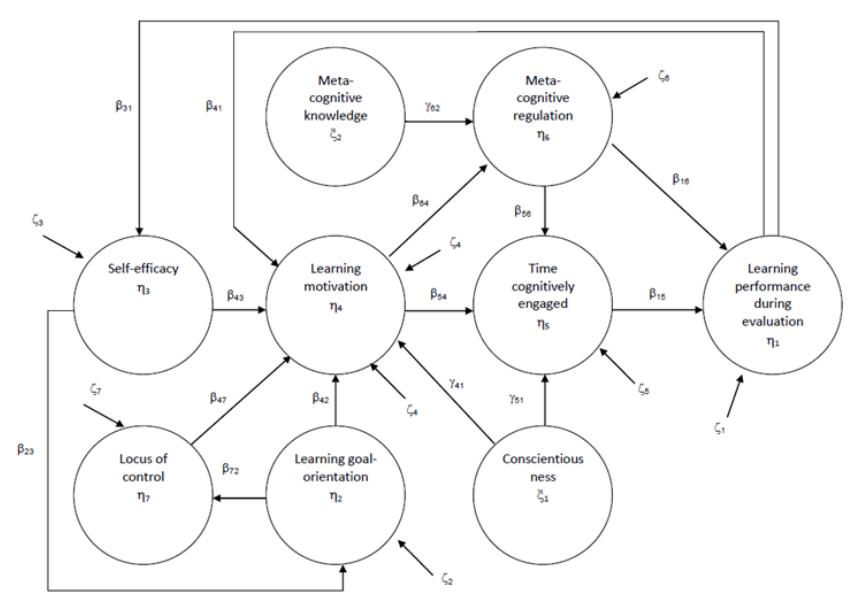

Figure 2: Reduced Van Heerden - De Goede learning potential structural model

The overarching substantive hypothesis of this study is that the learning potential structural model depicted in Figure 2 provides a valid description of the psychological process that determines the level of classroom learning performance and the level of learning performance during evaluation achieved by affirmative development learners (Hypothesis $2^{6}$ ). The overarching substantive research hypothesis can be dissected into the fifteen more detailed, path-specific substantive research hypotheses shown in Van Heerden (2013).

\section{Research design}

This study utilised an ex post facto research design due to the fact that the nature of the latent variables included in the reduced Van Heerden - De Goede learning potential structural model do not permit operationalisation through experimental manipulation. More specifically the ex post facto correlational research design, in which each latent variable is operationalised in terms of at least two or more indicator variables, was used to test the overarching and path-specific substantive research hypotheses.

\section{Statistical hypotheses}

If the overarching substantive research hypothesis is understood to mean that the structural model provides a perfect account of the manner in which learning competency potential latent variables affect classroom learning competencies and learning performance during evaluation, the substantive research hypothesis translates into the following exact fit null hypothesis:

\section{$\mathrm{H}_{03}: \mathrm{RMSEA}=0^{7}$ \\ $\mathrm{H}_{\mathrm{a} 3}: \mathrm{RMSEA}>0$}

If the overarching substantive research hypothesis is taken to mean that the structural model provides an approximate account of the manner in which learning competency potential latent variables affect classroom learning competencies and learning performance during evaluation the substantive research hypothesis translates into the following close fit null hypothesis:

$\mathrm{H}_{04}: \mathrm{RMSEA} \leq, 05$

$\mathrm{H}_{\mathrm{a} 4}: \mathrm{RMSEA}>, 05$

The fifteen detailed research hypotheses into which the overarching substantive research hypothesis was separated translate into the path coefficient statistical hypotheses shown in Table 1.

Table 1: Path coefficient statistical hypotheses

\begin{tabular}{|c|c|}
\hline Hypothesis 3: & Hypothesis 11: \\
\hline $\mathrm{H}_{05} \beta_{15}=0$ & $\mathrm{H}_{013}: \gamma_{41}=0$ \\
\hline $\mathrm{H}_{\mathrm{a} 5}: \beta_{15}>0$ & $\mathrm{H}_{\mathrm{a} 13}: \gamma_{41}>0$ \\
\hline Hypothesis 4: & Hypothesis 12 : \\
\hline $\mathrm{H}_{06}: \beta_{16}=0$ & $\mathrm{H}_{014}: \beta_{43}=0$ \\
\hline $\mathrm{H}_{\mathrm{a} 6}: \beta_{16}>0$ & $\mathrm{H}_{\mathrm{a} 14}: \beta_{43}>0$ \\
\hline Hypothesis 5: & Hypothesis 13: \\
\hline $\mathrm{H}_{07}: \beta_{56}=0$ & $\mathrm{H}_{015}: \beta_{23}=0$ \\
\hline $\mathrm{H}_{\mathrm{a} 7}: \beta_{56}>0$ & $H_{a 15}: \beta_{23}>0$ \\
\hline Hypothesis 6: & Hypothesis 14: \\
\hline $\mathrm{H}_{08}: \gamma_{62}=0$ & $\mathrm{H}_{016}: \beta_{47}=0$ \\
\hline $\mathrm{H}_{\mathrm{a} 8}: \gamma_{62}>0$ & $\mathrm{H}_{\mathrm{a} 16}: \beta_{47}>0$ \\
\hline Hypothesis 7: & Hypothesis 15: \\
\hline$\overline{\mathrm{H}_{09}: \beta_{54}=0}$ & $\mathrm{H}_{017}: \beta_{72}=0$ \\
\hline $\mathrm{H}_{\mathrm{a} 9}: \beta_{54}>0$ & $\mathrm{H}_{\mathrm{a} 17}: \beta_{72}>0$ \\
\hline Hypothesis 8: & Hypothesis $16:$ \\
\hline $\mathrm{H}_{010} \beta_{64}=0$ & $\mathrm{H}_{018}: \beta_{41}=0$ \\
\hline $\mathrm{H}_{\mathrm{a} 10}: \beta_{64}>0$ & $\mathrm{H}_{\mathrm{a} 18}: \beta_{41}>0$ \\
\hline Hypothesis 9: & Hypothesis 17: \\
\hline $\mathrm{H}_{011}: \beta_{42}=0$ & $\mathrm{H}_{019}: \beta_{31}=0$ \\
\hline $\mathrm{H}_{\mathrm{a} 11}: \beta_{42}>0$ & $\mathrm{H}_{\mathrm{a} 19}: \beta_{31}>0$ \\
\hline \multicolumn{2}{|l|}{ Hypothesis 10: } \\
\hline \multicolumn{2}{|l|}{$\mathrm{H}_{012}: \gamma_{51}=0$} \\
\hline \multicolumn{2}{|l|}{$\mathrm{H}_{\mathrm{a} 12}: \gamma_{51}>0$} \\
\hline
\end{tabular}

\footnotetext{
${ }^{7}$ The numbering of the statistical hypotheses reflect the fact that the success with which the latent variables in the elaborated learning potential structural model has been operationalised will be evaluated by testing the exact and close fit of the measurement model prior to fitting the comprehensive LISREL model.
}

${ }^{6}$ Hypothesis 1 refers to the measurement model. 


\section{Sampling}

The target population is the population of South African learners. Testing the validity of the reduced Van Heerden De Goede learning potential structural model on the target population is not practically feasible. Due to the affirmative action perspective from which this study stems, one would want to argue that the sample needs to consist of participants that qualify as affirmative development candidates. However, the other side of the coin argues that the value of the structural model developed for this study extends to all forms of formal training and teaching and is not restricted only to affirmative development candidates. The essence of the psychological dynamics governing learning performance in affirmative development programmes does not differ from those that govern learning performance in other teaching and training contexts. The assumption is that the same complex nomological network of latent variables that determine learning performance in affirmative development programmes also is at work to determine learning performance of learners not from previously disadvantaged backgrounds. The level of latent variables will, however, most likely differ across different teaching and training contexts. Diagnosing failures at learning requires identifying those determining latent variables that have inappropriately high or low levels. Success at learning is explained by the fact that the latent variables that determine learning performance have appropriate/optimal values. The fact that specific latent variables are flagged as important contributing variables to diagnostically explain the failure of disadvantaged learners to succeed at learning tends to erroneously suggest that these variables are uniquely relevant to explain the learning performance of disadvantaged learners. Advantaged learners succeed at learning because they are fortunate enough not to be held back by low levels on those latent variables flagged as important contributing variables to diagnostically explain the failure of disadvantaged learners to succeed at learning. Therefore, when it came to selecting a sample, it was deemed acceptable to draw a sample that includes participants that do not qualify as affirmative development candidates. Non-probability sampling was used to select a sample of 320 Grade 12 learners from three high schools to participate in the study. The schools are based in the Western Cape and consist of a socio-economically and racially diverse group of students. Institutional permission was obtained from the Western Cape Department of Education and the principal from the schools that participated in the study. Informed consent was further obtained from the parents of the Grade 12 learners as well as informed assent from the learners who participated in the study. Due to the non-probability sampling procedure that was used to select the sample it cannot be claimed that the sample is representative of the target population (Van Heerden, 2013).

\section{Measuring instruments}

Seven questionnaires were identified through a literature review as providing reliable and valid measures of the latent variables in the reduced Van Heerden - De Goede learning potential structural model. ${ }^{8}$

The Internality, Powerful others, and Chance Scales developed by Levenson and Miller (1976) was used to operationalise the locus of control construct, a measure developed by Button et al. (1996) was used to operationalise the goal-orientation construct and a sub-section of the Motivated Strategies for Learning Questionnaire (MSLQ) was administered to measure the construct of academic selfefficacy. The Meta-cognitive Awareness Inventory (MAI), as developed by Schraw and Dennison (1994), was utilised to operationalise the two dimensions of meta-cognition. The motivation to learn section of a combined questionnaire developed by Nunes (2003) to measure trainee motivation to learn and intention to learn was used (in a slightly revised format) to measure learning motivation. The Alphabetical Index of 204 Labels for 269 International Personality Item Pool IPIP Scales (retrieved May 28, 2011 from http://ipip.ori.org/newNEOKey.htm\#Conscientiousness) was used to measure conscientiousness and a sub-section of the Motivated Strategies for Learning Questionnaire (MSLQ) was administered to measure the construct of time cognitively engaged. Psychometric evidence in justification of the choice of measuring instruments is presented in Van Heerden (2013). Data was collected by means of a paperand-pencil format questionnaire (see Appendix A in Van Heerden, 2013). The participants completed the questionnaires during school hours in a Life Orientation class. Learning performance was represented through the learners' grade 12 first semester (term 1 and 2) academic results. More specifically, all the learners from the three schools included in this study had the subjects English $1^{\text {st }}$ language and Afrikaans $2^{\text {nd }}$ language and therefore marks for these subjects were used to represent Learning Performance. No psychometric evidence on the reliability and validity of these measures were available. This should be acknowledged as a methodological limitation since it really only makes sense to test the substantive hypotheses if confidence exists that the measured operational definitions succeeded in obtaining valid and reliable measures of the latent variables as constitutively defined.

\section{Missing values}

Multiple imputation (MI) was used to impute missing values. The multiple imputation method conducts several imputations for each missing value. In LISREL missing values for each case are substituted with the average of the values imputed in each of the data sets (Du Toit \& Du Toit, 2001). The advantage of the MI procedure is that all 320 cases are retained in the imputed data set (Du Toit \& Du Toit, 2001). The data in this study meets the requirements according to Mels (2010) for the use of the multiple

\footnotetext{
${ }^{8}$ The structural model contains nine latent variables. Two of these latent variables (meta-cognitive knowledge and meta-cognitive regulation) were measured with one questionnaire (Meta-cognitive Awareness Inventory) and learning performance during evaluation was measured by the academic marks received from the participating schools.
} 
imputation methods, namely, the observed variables should be measured on a scale comprising five or more scale values, the observed variables should not be excessively skewed (even though the null hypothesis of multivariate normality had been rejected) and less than $30 \%$ of the data should constitute missing values.

\section{Data analysis and results}

Item analysis, exploratory factor analysis, confirmatory factor analysis and structural equation modelling (SEM) were used to analyse the questionnaire data and to test the reduced Van Heerden - De Goede learning potential structural model as depicted in Figure 2.

\section{Item analysis}

To identify and eliminate possible items that do not contribute to an internally consistent description of the various latent variables forming part of the reduced Van Heerden - De Goede learning potential structural model, item analysis was performed on the items of the different measuring instruments. Item analyses were conducted on all the scales after imputation. Problematic items were not used to represent latent variables in the model and were not included in the calculation of composite indicator variables. Item analysis was conducted by means of SPSS Reliability Procedure (SPSS, 2011). The results for the item analysis are summarised in Table 2.

Table 2: Subscale statistics; a summary of results of the item analysis

\begin{tabular}{|c|c|c|c|c|c|c|c|}
\hline Subscale & $\begin{array}{c}\text { Sample } \\
\text { Size }\end{array}$ & Mean & $\begin{array}{l}\text { Number of } \\
\text { items }\end{array}$ & $\begin{array}{c}\text { Number of } \\
\text { items } \\
\text { deleted }\end{array}$ & $\begin{array}{l}\text { Number } \\
\text { of items } \\
\text { retained } \\
\text { in the } \\
\text { scale }\end{array}$ & $\begin{array}{l}\text { Standard } \\
\text { Deviation }\end{array}$ & $\begin{array}{c}\text { Cronbach } \\
\text { Alpha }\end{array}$ \\
\hline Conscientiousness & 320 & 38,065 & 12 & 1 & 11 & 12,209 & ,887 \\
\hline Academic self-efficacy & 320 & 47,663 & 9 & 0 & 9 & 7,801 &, 881 \\
\hline Learning motivation & 320 & 32,878 & 6 & 0 & 6 & 5,892 &, 855 \\
\hline Meta-cognitive knowledge & 320 & 72,684 & 17 & 0 & 17 & 13,297 &, 886 \\
\hline Meta-cognitive regulation & 320 & 134,119 & 35 & 0 & 35 & 27,851 & ,937 \\
\hline Learning goal-orientation & 320 & 45,281 & 8 & 0 & 8 & 6,700 & ,834 \\
\hline Time cognitively engaged & 320 & 32,388 & 9 & 3 & 6 & 5,449 &, 630 \\
\hline Internal locus of control & 320 & 36,622 & 8 & 1 & 7 & 12,209 &, 420 \\
\hline
\end{tabular}

The third item of the conscientiousness scale (Cons3) was flagged as problematic. The inter-item correlations of Cons 3 with the remainder of the items, the item-total correlation $(, 260)$, the squared multiple correlation $(, 140)$ and the increase in Cronbach's alpha $(, 887$ to, 897$)$ raised the concern that Cons 3 shares insufficient variance with the remainder of the item This basket of evidence was considered sufficient to justify the removal of this item. None of the items in the academic self-efficacy, learning motivation, meta-cognitive knowledge, meta-cognitive regulation and learning goal-orientation scales were flagged as problematic and all the items were retained in these five scales. The third item of the time cognitively engaged scale (Time3) was flagged as a problematic item. The Cronbach's alpha changing from ,630 to ,666 if the item is deleted, a low item-total correlation $(, 083)$ and a low squared multiple correlation $(, 071)$ prompted the decision to remove Time3. The deletion of Time3, however, brought Time 4 and Time5 to the fore as problematic items. Both items consistently correlated lower than the mean inter-item correlation with the other remaining items in the scale and reported low corrected item-total correlations (,228 and ,224 respectively) and low squared multiple correlations (,075 and ,095 respectively). Deletion of Time4 would result in a zero change to the Cronbach's alpha and the deletion of Time5 would lead to an increase in the Cronbach's alpha from ,666 to ,.668. Due to the fact that only Time5 would prompt an increase in the Cronbach's alpha, Time5 was removed from the scale while Time4 was retained. The analysis was subsequently re-run after the deletion of Time5. It then came to fore that the deletion of Time 4 would lead to an increase in the Cronbach's alpha from ,666 to ,670. Time 4 was therefore also removed from the scale. The analysis was again re-run, but no further items were flagged for deletion. The time cognitively engaged scale was therefore reduced from 9 to 6 items. Although the Cronbach's alpha of ,670 is somewhat worrying and substantially lower than the cut off of , 80 , it was decided to retain the construct in the structural model and continue performing subsequent analyses on the scale. The second item of the internal locus of control scale (ILocus2) was flagged as problematic. The low inter-item correlations of ILocus 2 with the remainder of the items, the low item-total correlation (,090), the low squared multiple correlation $(, 049)$ and the increase in Cronbach's alpha $(, 420$ to ,438) raised the concern that ILocus 2 shares insufficient variance with the remainder of the items in the scale. This basket of evidence was considered sufficient to justify the removal of this item. The internal locus of control scale was therefore reduced from 8 to 7 items. The item analysis was subsequently repeated on the remaining items but no further items could be identified for deletion to raise the Cronbach coefficient above the ,80 cut-off value. The Cronbach's alpha of ,438 was deemed unacceptably below the cut-off of , 80 , and concern was also raised by the general low and negative inter item correlations (ranging from -,004 to ,290) and low squared multiple correlations (ranging from ,048 to ,118). It was therefore decided that the scale could not be included in further analyses of the structural model. The latent variable locus of control and the path-specific hypotheses associated with this variable consequently had to be deleted from the fitted model. 


\section{Dimensionality analysis}

Specific design intentions guided the construction of the various scales used to operationalise the latent variables in the structural model (Figure 2) being tested in this study. The items comprising the scales and subscales were designed to operate as stimulus sets to which test takers respond with behaviour that is primarily an expression of a specific underlying latent variable. Unrestricted principal axis factor analyses with oblique rotation were performed on the various scales and subscales. The objective of the analyses was to evaluate this assumption and to evaluate the success with which each item, along with the rest of the items in the particular subscale, measures the specific latent variable it was designed to reflect. The items that were deleted in the preceding item analyses were not included in the factor analyses. The decision on how many factors are required to adequately explain the observed correlation matrix was based on the eigenvalue-greater-than-one rule and on the scree test (Tabachnick \& Fidell, 2001). Factor loadings of items on the factor they were designated to reflect will be considered satisfactory if they are greater than ,50. The adequacy of the extracted solution as an explanation of the observed inter-item correlation matrix was evaluated by calculating the percentage large $(>, 05)$ residual correlations. Table 3 provides a summary of the results of the dimensionality analyses.

Table 3: Summary of the results of the principal axis factor analyses

\begin{tabular}{|c|c|c|c|c|c|c|c|c|c|}
\hline Sub-scale & $\begin{array}{l}\text { Deter- } \\
\text { minant }\end{array}$ & $\mathrm{KMO}$ & $\begin{array}{c}\text { Bartlett } \\
\chi^{2}\end{array}$ & $\begin{array}{c}\% \\
\text { variance } \\
\text { explained }\end{array}$ & $\begin{array}{c}\text { \% residual } \\
\text { correlations } \\
>, 05\end{array}$ & $\begin{array}{l}\text { Largest } \lambda \\
\text { in single } \\
\text { factor } \Lambda\end{array}$ & $\begin{array}{c}\text { Smallest } \\
\lambda \text { in } \\
\text { single } \\
\text { factor } \Lambda\end{array}$ & $\begin{array}{c}\text { Number } \\
\text { of } \lambda<, 50 \\
\text { in single } \\
\text { factor } \Lambda\end{array}$ & $\begin{array}{c}\text { No. of } \\
\text { factors } \\
\text { extracted }\end{array}$ \\
\hline Conscientiousness & & ,896 & & & $15 \%$ & ,789 & ,482 & 1 & 2 \\
\hline Academic self-efficacy & & ,899 & & & $36 \%$ & ,797 &, 583 & 0 & 1 \\
\hline Learning motivation & &, 858 & & & $36 \%$ &, 808 &, 634 & 0 & 1 \\
\hline Meta-cognitive knowledge & & ,900 & & & & ,690 & ,361 & 5 & 3 \\
\hline Meta-cognitive regulation & & ,918 & & & $39 \%$ & ,720 & ,374 & 8 & 8 \\
\hline Learning goal-orientation & &, 864 & & & $39 \%$ &, 746 &, 537 & 0 & 1 \\
\hline Time cognitively engaged & & ,399 & & & &, 573 & 399 & 2 & 1 \\
\hline Internal locus of control & &, 613 & & & &,- 359 & 227 & 6 & 2 \\
\hline
\end{tabular}

Four of the scales passed the unidimensionality assumption as was originally hypothesised and five scales did not. In all five subscales where two factors were extracted based on the Kaiser criterion meaningful factor fission was obtained. In all instances the items were successfully forced onto a single factor solution. Thirteen items were deleted because of an inadequate loading on the extracted single factor (Van Heerden, 2013).

\section{Item parceling}

The structural model was fitted using item parcels as indicator variables. Little, Cunningham and Shahar (2002) argue that because fewer parameters are needed to fit a model when parcels are used, parcels are preferred when sample sizes are relatively small. The formation of linear composite measures has the additional advantage of creating more reliable indicator variables (Nunnally, 1978). Only the items that remained in the scale after the item and dimensionality analyses were used in the calculation of indicator variables to represent each of the latent variables in the structural model. Item parcels were created by calculating the mean of the even-numbered and uneven numbered items.

\section{Multivariate normality}

The default method of estimation when fitting measurement and structural models to continuous data (maximum likelihood) assumes that the distribution of indicator variables follow a multivariate normal distribution (Mels,
2003). Failure to satisfy this assumption results in incorrect standard errors and chi-square estimates (Du Toit \& Du Toit, 2001; Mels, 2003).

The univariate and multivariate normality of the composite item parcels in this study were evaluated via PRELIS. The null hypothesis that the data follows a multivariate normal distribution had to be rejected $\left(\chi^{2}=597,371 ; \mathrm{p}<, 05\right)$. An attempt at normalizing the distribution was subsequently attempted using PRELIS. The normalisation procedure succeeded in rectifying the univariate normality problem on the indicator variables but the null hypothesis of multivariate normality still had to be rejected $\left(\chi^{2}=211,839\right.$; $\mathrm{p}<, 05)$. The robust maximum likelihood estimation technique was therefore used on the normalized data as an alternative method of estimation more suited to non-normal data.

\section{Evaluating the fit of the measurement model}

Prior to fitting the learning potential structural model the fit of the combined measurement model was evaluated. To come to valid and credible conclusions on the validity of the structural model as a psychological explanation of learning performance, evidence needs to be lead that the operationalisation of the latent variables was successful by demonstrating that the indicator variables are indeed valid and reliable measures of the latent variables they are linked to. Unless the operational measures validly represent the latent variables they have been tasked to reflect, any assessment of the substantive relations of interest will be 
futile because it will not be clear as to what poor or good structural model fit means (Diamantopoulos \& Siguaw, 2000). The locus of control latent variable was omitted from the confirmatory factor analysis.

The full spectrum of fit indices for the measurement model is provided in Van Heerden (2013). The RMSEA value for the sample was ,033 with a $95 \%$ confidence interval of $(, 013-, 049)$. The null hypothesis of close fit was therefore not rejected. The distribution of standardised residual variances and covariances was only slightly negatively skewed with only four extreme residuals (circa 3\% of the residuals). This provides sufficient confidence in the measurement model parameters to warrant their interpretation. All the indicator variables loaded significantly on the latent variables that they were designed to reflect. All the completely standardised loadings exceeded ,71 (Hair et al., 2006) except for the loading of Afrikaans on learning performance during evaluation $(, 67)$ and Time 2 on time-cognitively-engaged $(, 68)$ which could be regarded as somewhat problematic. Examination of the modification index values calculated for $\boldsymbol{\Lambda}_{\mathbf{x}}$ and $\boldsymbol{\theta}_{\boldsymbol{\delta}}$ indicate that only four additional factor loadings (circa 4\%) and four covariance terms (circa 3\%) that, if set free, would significantly improve the fit of the model (Van Heerden, 2013). These small percentages comment very favourably on the fit of the model. It was therefore concluded that the operationalisation of the latent variables in the structural model was successful.

\section{Discriminant validity}

The 8 latent variables comprising the Van Heerden - De Goede learning potential structural model that was actually fitted are expected to correlate. Given that the 8 latent variables are conceputualised as 8 qualitatively distinct although related latent variables they should, however, not correlate excessively high with each other. The latent variable inter-correlations are reported in Table 4.35 in Van Heerden (2013). All the inter-latent variables are statistically significant $(\mathrm{p}<, 05)$ but for the correlation between learning performance during evaluation and learning goalorientation. Correlations are considered excessively high in this study if they exceed a value of 90. Judged by this criterion none of the correlations in the phi matrix are excessively high. One of the 28 inter-latent variable correlations exceed .80 but fall below , 88 . The fact that there are no excessively high correlations between the latent variables is, however, not very convincing evidence of discriminant validity. The possibility still exists that latent performance dimensions can correlate unity in the population while they correlate less than unity in the sample because of sampling error. To examine this possibility a 95\% confidence interval was calculated for each sample estimate in $\Phi$ utilising an Excel macro developed by Scientific Software International (Mels, 2010). If the value 1 is included in any confidence interval it implies that the null hypothesis $\mathrm{H}_{0}$ : $\phi=1$ cannot be rejected. Confidence in the claim that the two latent performance dimensions are unique, qualitatively distinct dimensions of the performance construct would thereby be seriously eroded. The $95 \%$ confidence intervals for $\phi_{\mathrm{ij}}$ are reported in Table 4.36 in Van Heerden (2013). None of the 28 confidence intervals include unity although one interval include the value (.90) earlier considered to be a critical value for excessively large correlations These findings indicate the discriminant validity of the Van Heerden - De Goede learning potential structural model latent variables

\section{Evaluating the fit of the structural model}

LISREL 8.8 was used to evaluate the fit of the comprehensive learning potential structural model. Robust maximum likelihood estimation method was used to produce the estimates. An admissible final solution of parameter estimates for the revised reduced learning potential structural model was obtained after 33 iterations. A subset of the fit indices provided by LISREL is presented in Table 4.

\section{Table 4: Goodness of fit statistics for the original learning potential structural model}

Degrees of Freedom $=90$
Normal Theory Weighted Least Squares Chi-Square $=310,48(\mathrm{P}=0,0)$
Satorra-Bentler Scaled Chi-Square $=281,06(\mathrm{P}=0,0)$
Root Mean Square Error of Approximation $(\mathrm{RMSEA})=0,082$
90 Percent Confidence Interval for RMSEA $=(0,071 ; 0,092)$
P-Value for Test of Close Fit $(\mathrm{RMSEA}<0,05)=0,00$
Normed Fit Index $(\mathrm{NFI})=0,96$
Non-Normed Fit Index $(\mathrm{NNFI})=0,96$
Parsimony Normed Fit Index $(\mathrm{PNFI})=0,72$
Comparative Fit Index $(\mathrm{CFI})=0,97$
Incremental Fit Index $(\mathrm{IFI})=0,97$
Relative Fit Index $(\mathrm{RFI})=0,95$
Root Mean Square Residual $(\mathrm{RMR})=0,56$
Standardized RMR $=0,20$
Goodness of Fit Index $(\mathrm{GFI})=0,89$
Adjusted Goodness of Fit Index $(\mathrm{AGFI})=0,84$
Parsimony Goodness of Fit Index $(\mathrm{PGFI})=0,59$

The p-value associated with the Satorra-Bentler $\chi^{2}$ value in Table 4 clearly indicates a significant test statistic $(\mathrm{p}<, 05)$. The Root Mean Square Error of Approximation (RMSEA) of ,082 indicates poor fit. The p-value associated with the sample RMSEA estimate indicates that the close fit null hypothesis $(\mathrm{RMSEA} \leq .05)$ has to be rejected. The reduced Van Heerden-De Goede structural model did not show good fit. Since the reduced structural model was unable to reproduce the observed covariance matrix to a degree of accuracy that warranted any faith in the structural model and the derived parameter estimates further interpretation of the derived model parameter estimates was therefore not undertaken. The modification indices calculated by LISREL were subsequently inspected to explore possible ways of improving the fit of the model. ${ }^{9}$

\footnotetext{
${ }^{9}$ This begs the question whether it is permissible to inspect the modification indices for $\mathbf{B}$ and $\Gamma$ when the comprehensive model fitted poorly. The lack of fit precludes placing any faith in the $\beta_{\mathrm{ij}}$ and $\gamma_{\mathrm{ij}}$ estimates as such. Why regard the modification estimates as credible? In this study it is argued that this procedure is
} 


\section{Modification of the Van Heerden-De Goede learning potential structural model}

Model modification indices answer the question whether freeing any of the currently fixed parameters in the structural model will significantly improve the fit of the model by calculating the extent to which the $\chi^{2}$ fit statistic decreases when each of the currently fixed parameters in the model is freed and the model re-estimated (Jöreskog \& Sörbom, 1998). Structural parameters currently fixed to zero with large modification index values $(>6,6349)$ are parameters that, if set free, would improve the fit of the model significantly $(\mathrm{p}<, 01)$ (Diamantopoulos \& Siguaw, 2000; Jöreskog \& Sörbom, 1998). Parameters with high MI values should, however, only be freed if it makes substantive sense to do so (Kelloway, 1998). A convincing theoretical argument should be put forward in support of the proposed causal linkage. The magnitude of the completely standardised expected change should moreover be substantial enough to warrant freeing the parameter. The sign of the completely standardised expected change should in addition make sense in terms of the theoretical argument put forward in support of the proposed path (Jöreskog \& Sörbom, 1998).

For the purpose of modifying the reduced structural model depicted in Figure 2 only the $\boldsymbol{\Gamma}$ and $\mathbf{B}$ matrices were inspected. The modification indices for $\Gamma$ and $\mathbf{B}$ are shown in Table 4.38 and in Table 4.39 in Van Heerden (2013). The fixed off-diagonal elements of the variance-covariance matrix $\boldsymbol{\Psi}$ were not considered. Putting forward a theoretical rational for freeing currently fixed covariance terms in $\boldsymbol{\Psi}$ in a cross-sectional research design would require the introduction of additional latent variables currently not included in the model. Neither were the fixed off-diagonal elements of the variance-covariance matrix $\Theta_{\delta}$ considered.

\section{First iteration}

The path with the highest modification index value (131.38) was that between meta-cognitive knowledge and learning performance. The critical question is whether the proposed path makes substantive sense. A relationship between metacognitive knowledge to learning performance does make sense, however not necessarily a direct relationship. The relationship between meta-cognitive knowledge to learning performance should be mediated by meta-cognitive regulation as depicted in the learning potential structural model in Figure 2. The individual's meta-cognitive knowledge is put into motion via the behaviour of metacognitive regulation and it is meta-cognitive regulation that then ultimately positively influences learning performance. A path between meta-cognitive knowledge to learning

permissible because the modification indices reflect the change in the normal theory chi-square sample estimate if a currently fixed element in B or $\Gamma$ would be freed and the model re-estimated. The credibility of the chi-square fit statistic is not under suspicion when the model fits poorly. The credibility of the expected chance values would, however, probably have to be regarded with some suspicion. performance was therefore not added and the next modification was considered.

After rejecting the suggested additional path between metacognitive knowledge and learning performance, the path with the second largest modification index $(125,15)$ was considered for modification, namely the path between metacognitive knowledge and academic self-efficacy. Exploring this train of thought, it would mean that an individual with higher levels of meta-cognitive knowledge (in terms of the components parts therefore higher levels of declarative-, procedural- and conditional knowledge) would have higher levels of academic self-efficacy. In other words, an individual who knows more strategies, knows how to use these strategies and knows when to use these strategies would have a higher belief in their own ability to learn (academic self-efficacy). It does make substantive theoretical sense that an individual who knows more about how to learn would have higher levels of belief in their own ability to learn. The magnitude of the completely standardised expected change in addition was also substantial enough to support the addition of this path. In addition the question was also considered whether any of the existing paths should be removed. Analysis of the unstandardised beta matrix for the fitted model (Van Heerden, 2013) revealed two statistically insignificant paths $(\mathrm{p}<, 05)$. Rather surprisingly, the path between time cognitively engaged and learning performance was not statistically significant $(\mathrm{p}>, 05)$ as well as the path between learning performance and learning motivation $(\mathrm{p}>, 05)$. No support is therefore found for the hypothesis of a feedback relationship between learning performance and learning motivation. Besides these two insignificant relationships all the other hypotheses in the beta matrix were supported. Equally surprising the path between conscientiousness and time cognitively engaged was also not statistically significant ( $p>, 05)$ (Van Heerden, 2013).

The structural model was therefore in the first iteration modified by deleting the paths between time cognitively engaged and learning performance and between learning performance and learning motivation and by inserting the path from meta-cognitive knowledge to academic selfefficacy. With these changes the structural model was fitted again.. The null hypothesis of exact fit was again rejected $(\mathrm{p}<, 05)$. The sample estimate of RMSEA $(, 058)$ and the $90 \%$ confidence interval for RMSEA $(, 046-, 069)$ indicated reasonable fit. The null hypothesis of close fit cannot be rejected $(\mathrm{p}=, 296)$. The modifications to the initial structural model have significantly improved the fit of the model to the data (Van Heerden, 2013).

\section{Second iteration}

The unstandardised beta and gamma matrices (Van Heerden, 2013) were examined to determine whether any further paths needed to be deleted from the model that emerged from the first round of modification. All the relationships were found to be significant $(p<, 05)$. The the 
newly inserted path from meta-cognitive knowledge to selfefficacy was statistically significant $(\mathrm{p}<, 05)$.

The newly calculated modification indices for the gamma and beta matrices were examined for the possible addition of further paths to the model. The path with the highest modification index value $(57,38)$ is that between metacognitive knowledge and learning goal-orientation (Van Heerden, 2013). A logical theoretical argument can be put forward to support this relationship. As was discussed during the literature review, individuals with a learning goal-orientation seek to develop competence by acquiring new skills and mastering novel situations. An individual with a learning goal-orientation has the goal to learn and acquire new knowledge. Also referring back to the literature review, an individual high in meta-cognitive knowledge will have knowledge about learning strategies (declarative knowledge), will know how to use learning strategies (procedural knowledge) and will also know when and why it is optimal to use which learning strategies (conditional knowledge). Considering the above, it makes sense to argue that an individual who knows how to learn (meta-cognitive knowledge) will be more likely to want to learn (learning goal-orientation). The magnitude of the completely standardised expected change was substantial enough to support the addition of this path.

The structural model was therefore in the second iteration only modified by inserting the path from meta-cognitive knowledge to learning goal-orientation. With this change the structural model was fitted again. The null hypothesis of exact fit is again rejected $(\mathrm{p}<, 05)$. The sample estimate of RMSEA (,046) and the $90 \%$ confidence interval for RMSEA (,033-,059) indicates good fit. The null hypothesis of close fit cannot be rejected $(\mathrm{p}=, 68)$. The modifications to the structural model have improved the fit of the model to the data (Van Heerden, 2013).

\section{Third iteration}

The unstandardised beta and gamma matrices were examined to determine whether any further paths needed to be deleted from the model that emerged from the second round of modification. The path between self-efficacy and learning goal-orientation was no longer statistically significant $(\mathrm{p}>, 05)$ in the revised model. The newly inserted path from meta-cognitive knowledge to learning goalorientation was statistically significant $(\mathrm{p}<, 05)$.

The modification indices in the gamma and beta matrices were again also examined for the possible addition of paths to the model. Although parameters with large modification index values $(>6,6349)$ were present in the beta matrix (Van Heerden, 2013), either no substantive theoretical argument could be found to support the addition of the paths or the completely standardised change did not to support the addition of the paths. Therefore no paths were added to the structural model at this stage of the analysis. The structural model was therefore in the third iteration only modified by deleting the path from self-efficacy to learning goalorientation. With this change the structural model was fitted again (Van Heerden, 2013).

An admissible final solution of parameter estimates for the modified learning potential structural model was obtained after 11 iterations. The completely standardised solution for the comprehensive LISREL model is depicted in Figure 3. The full spectrum of fit indices provided by LISREL to assess the absolute fit of the model is presented in Table 5.

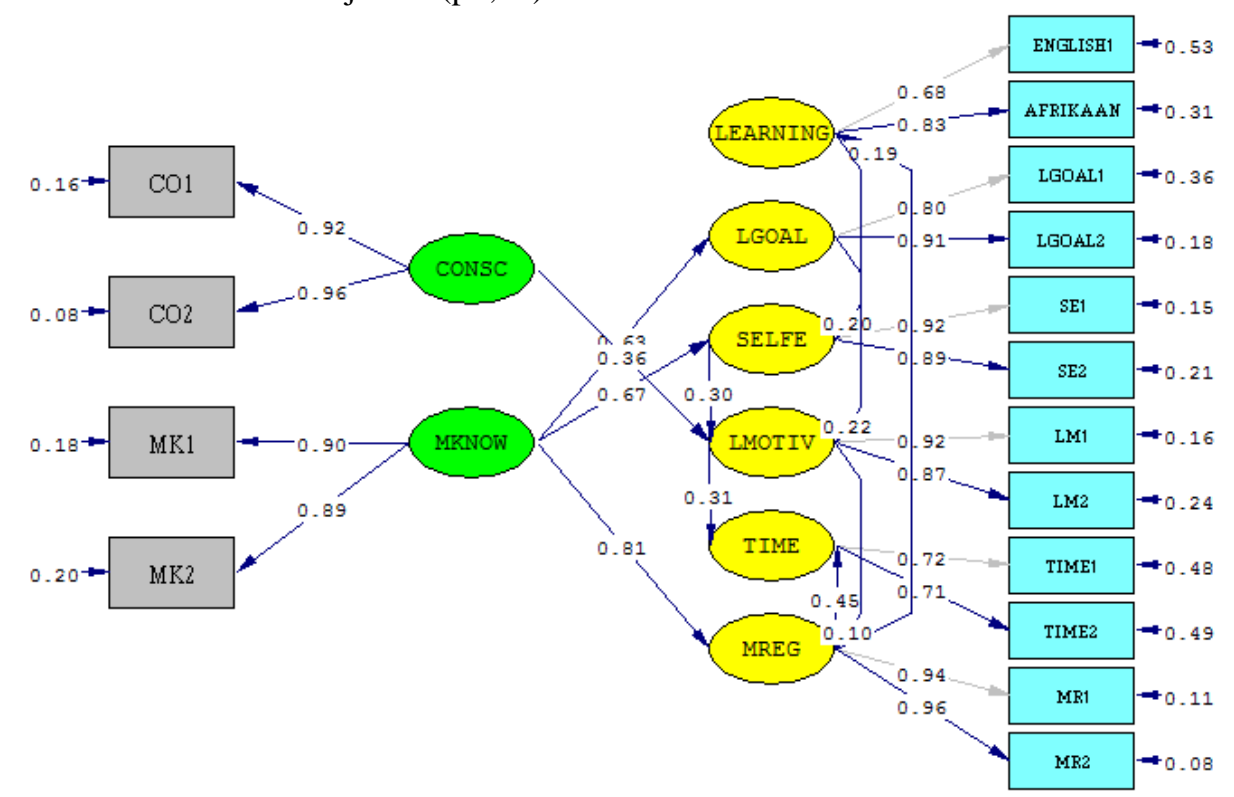

Figure 3: Representation of the modified Van Heerden-De Goede learning potential structural model 
Table 5: Goodness of fit statistics for the learning potential structural model (after third modification)

\begin{tabular}{ll}
\hline Degrees of Freedom $=92$ & Independence AIC $=7368,87$ \\
\hline Minimum Fit Function Chi-Square $=176,58(\mathrm{P}=0,00)$ & Model AIC $=240,87$ \\
Normal Theory Weighted Least Squares Chi-Square $=171,24(\mathrm{P}=0,00)$ & Saturated AIC $=272,00$ \\
Satorra-Bentler Scaled Chi-Square $=152,87(\mathrm{P}=0,00)$ & Independence CAIC $=7445,16$ \\
Chi-Square Corrected for Non-Normality $=262,84(\mathrm{P}=0,0)$ & Model CAIC $=450,68$ \\
Estimated Non-centrality Parameter $(\mathrm{NCP})=60,87$ & Saturated CAIC $=920,49$ \\
90 Percent Confidence Interval for NCP $=(30,75 ; 98,89)$ & Normed Fit Index $(\mathrm{NFI})=0,98$ \\
Minimum Fit Function Value $=0,55$ & Non-Normed Fit Index $(\mathrm{NNFI})=0,99$ \\
Population Discrepancy Function Value $(\mathrm{F} 0)=0,19$ & Parsimony Normed Fit Index $(\mathrm{PNFI})=0,75$ \\
90 Percent Confidence Interval for F0 $=(0,096 ; 0,31)$ & Comparative Fit Index $(\mathrm{CFI})=0,99$ \\
Root Mean Square Error of Approximation $(\mathrm{RMSEA})=0,046$ & Incremental Fit Index $(\mathrm{IFI})=0,99$ \\
90 Percent Confidence Interval for RMSEA $=(0,032 ; 0,058)$ & Relative Fit Index $(\mathrm{RFI})=0,97$ \\
P-Value for Test of Close Fit $(\mathrm{RMSEA}<0,05)=0,71$ & Critical N $(\mathrm{CN})=264,90$ \\
Expected Cross-Validation Index $(\mathrm{ECVI})=0,76$ & Root Mean Square Residual $(\mathrm{RMR})=0,39$ \\
90 Percent Confidence Interval for ECVI $=(0,66 ; 0,87)$ & Standardized RMR $=0,047$ \\
ECVI for Saturated Model $=0,85$ & Goodness of Fit Index $(\mathrm{GFI)}=0,94$ \\
ECVI for Independence Model $=23,10$ & Adjusted Goodness of Fit Index $(\mathrm{AGFI})=0,91$ \\
Chi-Square for Independence Model with 120 Degrees of Freedom $=7336,87$ & Parsimony Goodness of Fit Index $(\mathrm{PGFI})=0.63$
\end{tabular}

The null hypothesis of exact fit was rejected $(\mathrm{p}<, 05)$. There is a significant discrepancy between the covariance matrix implied by the structural model and the observed covariance matrix (Kelloway, 1998). The structural model was not able to reproduce the observed covariance matrix to a degree of accuracy that can be explained in terms of sampling error only. The normed chi-square statistics $(1,66)$ suggest that the model fits the data well. The sample estimate of RMSEA $(, 046)$ and the $90 \%$ confidence interval for RMSEA (,032$, 058)$ indicates good to reasonable model fit. The null hypothesis of close model fit $\left(\mathrm{H}_{0}\right.$ : RMSEA $\left.\leq, 05\right)$ was not rejected ( $\mathrm{p}>, 05)$ (Van Heerden, 2013).

The model ECVI $(, 76)$ is smaller than the value obtained for the independence model $(23,10)$. The model ECVI $(, 76)$ is also smaller than the saturated model $(, 85)$. The model AIC $(240,87)$ also achieved a value lower than both the independence model $(7368,87)$ and the saturated model (272,00). Similarly, the CAIC $(450,68)$ also achieved a value lower than both the independence model $(7445,16)$ and the saturated model $(920,49)$. Therefore, a model more closely resembling the fitted model seems to have a better chance of being replicated in a cross-validation sample than the independence and saturated models. The model produced a SRMR of ,047 indicative of good model fit (Diamantopoulos \& Siguaw, 2000).

Only seven covariance terms in the observed sample covariance matrix (circa 5\%) were substantially underestimated (Van Heerden, 2013). This comments favourably on the fit of the modified structural model. The stem-and-leaf plot was slightly positively skewed (Van Heerden, 2013). The estimated model parameters therefore tended to underestimate the observed covariance terms more than they tended to overestimate them. The results of the overall fit assessment shown in Table 5 along with the rest of the evidence suggested that good model fit was achieved for the revised learning potential structural model.

\section{Interpretation of structural model parameter estimates}

The good model fit that was obtained warrants the interpretation of the structural model parameter estimates. The completely standardised beta matrix ${ }^{10}$ depicted in Table 6 indicate that all the path coefficient estimates in $\mathbf{B}$ were statistically significant $(\mathrm{p}<, 05)$ and the sign of all estimates was in-line with the nature of the hypothesised effects.

Table 6: Unstandardised beta matrix

\begin{tabular}{|c|c|c|c|c|c|c|}
\hline & Learning & Lgoal & Selfe & Lmotiv & Time & Mreg \\
\hline LEARNING & & & & & & $\begin{array}{c}0,19 \\
(0,07) \\
2,58\end{array}$ \\
\hline LGOAL & & & & & & \\
\hline SELFE & $\begin{array}{c}0,20 \\
(0,05) \\
3,61\end{array}$ & & & & & \\
\hline LMOTIV & & $\begin{array}{c}0,22 \\
(0,06) \\
3,44\end{array}$ & $\begin{array}{c}0,30 \\
(0,06) \\
4,76\end{array}$ & & & \\
\hline TIME & & & & $\begin{array}{c}0,31 \\
(0,09)\end{array}$ & & $\begin{array}{c}0,45 \\
(0,09)\end{array}$ \\
\hline MREG & & & & $\begin{array}{c}3,52 \\
0,10 \\
(0,05) \\
1,96\end{array}$ & & 5,18 \\
\hline
\end{tabular}

Table 6 indicates that learning performance was found to be statistically significantly and positively determined by the extent to which learners engage in meta-cognitive regulatory behaviour. The relationship postulated by hypothesis $4^{11}$ between meta-cognitive regulation and learning performance in the structural model is corroborated. Learning goal-orientation has a statistically significant effect on learning motivation, thereby providing support for the casual relationship hypothesised by hypothesis 9

\footnotetext{
${ }^{10}$ The unstandardised and completely standardized beta matrices were combined in Table 6.

${ }^{11}$ Path-specific substantive research hypotheses are shown in Van Heerden (2013).
} 
between learning goal-orientation and learning motivation. Furthermore, self-efficacy has a statistically significant effect on learning motivation, thereby providing support for the relationship as hypothesised by hypothesis 12 in the structural model. Table 6 also indicates that learning motivation has a statistically significant effect on time cognitively engaged which corroborates the hypothesised relationship (hypothesis 7) between learning motivation and time cognitively engaged. Learning motivation also has a statistically significant effect on meta-cognitive regulation, thereby providing support for the relationship as hypothesised by hypothesis 8 in the structural model. Furthermore, meta-cognitive regulation has a statistically significant effect on time cognitively engaged, thereby providing support for the casual relationship hypothesised by hypothesis 5 between meta-cognitive regulation and time cognitively engaged. Lastly, it is indicated that learning performance has a statistically significant effect on selfefficacy. This corroborates the feedback relationship hypothesised by hypothesis 17 between learning performance and self-efficacy. $\mathrm{H}_{06}, \mathrm{H}_{07}, \mathrm{H}_{09}, \mathrm{H}_{010}, \mathrm{H}_{011}, \mathrm{H}_{014}$ and $\mathrm{H}_{019}$ (see Table 1) could therefore be rejected. The paths associated with $\beta_{23}$ and $\beta_{41}$ were deleted during the refinement of the model because of the insignificance of the paths. $\mathrm{H}_{015}, \mathrm{H}_{018}$ were therefore not rejected. Locus of control was deleted from the model because the operationalisation of this latent variable failed. $\mathrm{H}_{016}$ and $\mathrm{H}_{017}$ were therefore never tested.

The completely standardised gamma matrix ${ }^{12}$ is depicted in Table 7 and describes the slope of the relationships between the exogenous variables and the endogenous variables. The results depicted in Table 7 indicate that all the path coefficient estimates in $\Gamma$ were statistically significant $(\mathrm{p}<, 05)$.

Table 7: Completely standardised gamma matrix

\begin{tabular}{lcc}
\hline & CONSC & MKNOW \\
\hline LEARNING & & 0,63 \\
LGOAL & & $(0,07)$ \\
& & 9,57 \\
SELFE & & 0,67 \\
& & $(0,05)$ \\
LMOTIV & 0,36 & 12,18 \\
& $(0,07)$ & \\
TIME & 5,41 & \\
MREG & & 0,81 \\
& & $(0,06)$ \\
& & 13,80 \\
\hline
\end{tabular}

Table 7 indicates that meta-cognitive knowledge has a statistically significant effect on learning goal-orientation, thus the relationship postulated between meta-cognitive knowledge and learning goal-orientation in the structural model is corroborated. It is also indicated that meta-

12 The unstandardised and completely standardized gamma matrices were combined in Table 7. cognitive knowledge has a statistically significant effect on self-efficacy, thereby providing support for the casual relationship hypothesised between meta-cognitive knowledge and self-efficacy. Furthermore, meta-cognitive knowledge has a statistically significant effect on metacognitive regulation which similarly corroborates the hypothesised relationship between meta-cognitive knowledge and meta-cognitive regulation in the structural model. Lastly, Table 7 indicates that conscientiousness has a statistically significant effect on learning motivation and thereby providing support for the relationship as hypothesised in the structural model. $\mathrm{H}_{06}, \mathrm{H}_{07}, \mathrm{H}_{09}, \mathrm{H}_{010}$, $\mathrm{H}_{011}, \mathrm{H}_{014}$ and $\mathrm{H}_{019}$ (see Table 1) could therefore be rejected. The path associated with $\gamma_{51}$ was deleted during the refinement of the model because of the insignificance of the path. $\mathrm{H}_{012}$ was therefore not rejected.

Diamantopoulos and Siguaw (2000) suggest that additional insights can be obtained by considering the completely standardised and parameter estimates provided by LISREL. The completely standardised and parameter estimates are not affected by differences in the unit of measurement of the latent variables and can thus be compared across equations. The completely standardised and parameter estimates reflect the average change, expressed in standard deviation units, in the endogenous latent variables, directly resulting from a one standard deviation change in an endogenous or exogenous latent variable to which it has been linked, holding the effect of all other variables constant (Diamantopoulos \& Siguaw, 2000). The completely standardised and parameter estimates are depicted in Tables 6 and 7.

Table 6 and Table 7 indicate that of the significant effects, the effect of meta-cognitive knowledge on meta-cognitive regulation is the most pronounced, followed by the effect of meta-cognitive knowledge on self-efficacy and metacognitive knowledge on learning goal-orientation. It is interesting to note that the latter two relationships were not originally hypothesised but were added later after running the analysis and investigating the modification indices.

A significant beta or gamma path coefficient estimate does not mean proof of a causal effect. When using correlational data obtained via an ex-post facto research design (as in this study), it is not possible to isolate the empirical system sufficiently so that the nature among the variables can be described as causal. The ex post facto nature of the research design therefore precludes the drawing of causal inferences from significant path coefficients.

Table 8 indicates the $\mathrm{R}^{2}$ values for the six endogenous latent variables. As is evident from Table 8 the learning potential structural model successfully accounts for the variance in meta-cognitive regulation and self-efficacy. However, the learning potential structural model was less successful in explaining variance in learning motivation, time cognitively engaged, learning goal-orientation and in learning performance. The model's inability to account for the variance in these latent variables is somewhat disappointing. 
The results of the latter could however in part be attributed to the fact that the more cognitively orientated learning competencies (transfer of knowledge and automatisation) were excluded from the current structural model, as well as the cognitive learning competency potential latent variables (information processing capacity and abstract thinking capacity). This line of reasoning, however to some degree undermines the initial argument that it is unlikely that learning performance solely depends on cognitive factors.

Table 8: $R 2$ values for the six endogenous latent variables

\begin{tabular}{cccccc}
\hline LEARNING & LGOAL & SELFE & LMOTIV & TIME & MREG \\
0,04 & 0,39 & 0,53 & 0,48 & 0,45 & 0,76 \\
\hline
\end{tabular}

\section{Discussion}

To assist organisations to identify the individuals who will gain maximum benefit from affirmative action skills development opportunities and to create the condition that will maximise the likelihood that those individuals that are admitted on to the programme will succeed, an understanding is required of the factors that determine whether or not a learner will be successful if entered into an affirmative action skills development opportunity. The primary objective of this study was to expand on De Goede's (2007) learning potential structural model. Noncognitive factors were added to the De Goede (2007) learning potential structural model in order to gain a deeper understanding of the complexity underlying learning and the determinants of learning performance. Two competencies were added to the model namely meta-cognitive regulation and time cognitively engaged. Furthermore, the competency potential latent variables meta-cognitive knowledge, learning motivation, conscientiousness, academic selfefficacy, and learning goal-orientation were added to the model.

No support was found for the hypothesis that time cognitively engaged influences learning performance. Secondly, no support was found for the hypothesis of a feedback relationship between learning performance and learning motivation. Furthermore, analysis of the gamma matrix indicated that the path between conscientiousness and time cognitively engaged was insignificant therefore indicating that no support was found for the hypothesis that conscientiousness influences time cognitively engaged. The lack of support for these three paths was rather surprising. The theoretical arguments underpinning all three these hypotheses were strong and convincing. All three hypotheses involve at least one latent variable whose operationalisation to some degree was problematic. One indicator of time cognitively engaged and one indicator of learning performance did not reflect the latent variable that it was tasked to represent to the standards that were set. The question arises whether the lack of support for these hypotheses is due to problems with the operationalisation of time cognitively engaged and learning performance or whether it is due to flaws in the theorising. This ambiguity is exactly the problem that the initial item analysis, dimensionality analysis and confirmatory factor analysis attempted to prevent. In a study of this nature the ability to respond to feedback from these analyses and to appropriately modify and/or replace measures and to repeat data gathering is, however, limited by practical considerations.

Conscientiousness was found to positively influence learning motivation. An individual that is ambitious, energetic, controls his/her inclinations, diligent, careful, practical and with 'the will to succeed,' (Eilam et al., 2009) will be more motivated and driven to learn. Academic selfefficacy was shown to positively influence learning motivation. A strong belief in one's academic capabilities increases motivation to learn. It makes sense that an individual who believes in their ability to be successful in academic tasks, will be more motivated during academic tasks than an individual who does not believe in their ability to be successful in academic tasks. Learning motivation was shown to influence time cognitively engaged as well as meta-cognitive regulation. The more an individual is motivated to learn, firstly the more time that individual will spend cognitively engaged in learning tasks and secondly the more likely that individual will be to utilise strategies such as planning, organising, regulating and monitoring cognitive resources for increased efficiency during learning. Learning motivation was therefore found to be the driver that compels individuals into engaging the behaviours that leads to increased learning. Meta-cognitive knowledge was found to positively influence two competency potentials in the structural model namely academic self-efficacy and learning goal-orientation as well as positively influence the competency meta-cognitive regulation. Although not initially hypothesised during the theorising, examination of the modification indices after an initial analysis of the model indicated a relationship between meta-cognitive knowledge and academic self-efficacy. In other words, an individual with higher levels of meta-cognitive knowledge (in terms of the components parts therefore higher levels of declarative-, procedural- and conditional knowledge) would have higher levels of academic self-efficacy. An individual who knows more strategies, knows how to use these strategies and knows when to use these strategies would have a higher belief in their own ability to learn (academic self-efficacy). It does make substantive sense that an individual who knows more about how to learn would have higher levels of belief in their own ability to learn. Also not initially included during the theorising but only added after an examination of the modification indices, is the evidence of a positive relationship between meta-cognitive knowledge and learning goal-orientation. A logical theoretical argument can be put forward to support this relationship. Individuals with a 
learning goal-orientation seek to develop competence by acquiring new skills and mastering novel situations. An individual with a learning goal-orientation has the goal to learn and acquire new knowledge. An individual high in meta-cognitive knowledge will have knowledge about learning strategies (declarative knowledge), will know how to use learning strategies (procedural knowledge) and will also know when and why it is optimal to use which learning strategies (conditional knowledge). It therefore makes sense to argue that an individual who knows how to learn (metacognitive knowledge) will be more likely to want to learn (learning goal-orientation). The results also indicated that meta-cognitive knowledge positively affects the competency meta-cognitive regulation. This relationship makes sense as the argument to support this stance states that if students cannot distinguish between what they know and do not know, they can hardly be expected to exercise control over their learning activities or to select appropriate strategies to progress in their learning. The results moreover indicated that meta-cognitive regulation positively affects learning performance during evaluation. Meta-cognitive regulation was the only construct in the learning potential structural model that evidenced a direct relationship with learning performance during evaluation. The relationship between meta-cognitive regulation and learning performance during evaluation means that an individual who engages in cognitive processes such as planning strategies and the allocation of resources, monitoring of progress and the effectiveness of strategies and eventually evaluating their own learning, will be more successful at learning performance during evaluation than an individual who does not regulate their own cognitive processes during learning. Learning performance was also found to have a feedbackeffect in the learning potential structural model in that it influences academic self-efficacy. This is in line with the theorising of Bandura $(1986,1977)$ that the most influential source of self-efficacy beliefs is the interpreted result of one's previous performance, or learning experience. Individuals engage in tasks and activities, interpret the results of their actions, and use the interpretations to develop beliefs about their capability to engage in subsequent tasks or activities.

\section{Managerial implications}

Non-malleable determinants of classroom learning performance and eventual learning performance during evaluation represent predictor constructs that warrant consideration for inclusion in a learning potential selection battery that is used to select disadvantaged candidates with learning potential into the affirmative development opportunity $^{13}$. A learning potential selection battery that

\footnotetext{
${ }^{13}$ This raises a number of important questions. Are candidates directly selected into a job and developed as appointed employees? This would imply a single-stage selection procedure and would align well with the thinking on affirmative action as outlined in the Employment Equity Act (Republic of South Africa, 1998). Or are candidates first selected into the affirmative development opportunity and subsequently evaluated on their extent to which they benefited from the development and then considered, along
}

includes conscientiousness, fluid intelligence, information processing capacity and learning goal-orientation as relatively non-malleable person-centered variables should be able to control the level of classroom learning performance by controlling the quality of the candidates that flow into the affirmative development opportunity.

A second practical implication includes using interventions/techniques to develop and enhance the malleable competency potentials of candidates admitted into the affirmative action skills development programme. Malleable latent variables offer the possibility to affect classroom learning performance by manipulating the quality of learners before they have been admitted onto the affirmative development programme and once they have been admitted. The revised Van Heerden - De Goede learning potential structural model suggests that learning motivation and self-efficacy are two latent variables that should be considered in this regard. Learning motivation depends on the expectancy that exerting effort will result in successful learning performance during evaluation $(\mathrm{P}(\mathrm{E} \rightarrow \mathrm{P}))$ and the instrumentality of high learning performance during evaluation in attaining positively valences outcomes $\left(\mathrm{P}\left(\mathrm{P} \rightarrow \mathrm{O}_{\mathrm{i}}\right) \times \mathrm{Val}\left(\mathrm{O}_{\mathrm{i}}\right)\right.$. Learning motivation can therefore be enhanced by increasing the expectancy of high learning performance during evaluation (by increasing academic self-efficacy for example) and by increasing the instrumentality of high learning performance during evaluation (by communicating the fact that appointment, promotion and advancement in the organisation is conditional on learning performance during evaluation). Academic-self efficacy can be developed (prior to admission to an affirmative development programme as well as during the development programme) in those candidates selected for admission to the programme. Literature provides extensive information of the development of self-efficacy. Self-efficacy is affected by five primary sources: (a) learning experience, (b) vicarious experience, (c) imaginal experiences, (d) social persuasion, and (e) physiological states (Bandura, 1997). It is disconcerting to note that the sources of self-efficacy quite strongly suggest that Apartheid policies and practices most likely would have impacted negatively on the self-efficacy of many Black South Africans.

with not-previously disadvantaged candidates, for selection into a job? This would imply a two-stage selection procedure that is somewhat at odds with the thinking of the Employment Equity Act (Republic of South Africa, 1998). A second question relates to the nature of the criterion against which the learning potential selection battery should be validated. The criterion could either be the level to which candidates succeed to rise on the learning performance during evaluation scale or it could be the distance on the scale over which the candidate improved. A third question relates to the manner in which the predictor information should be combined so as to assign candidates to a treatment category (i.e., accept or reject). Specifically the question is whether the traditional multiple regression model should be used or whether the ability of LISREL to derive latent scores from indicator variable scores along with the structural equations derived for the fitted learning potential structural model for the study sample. 
Furthermore, literature on meta-cognition suggest that individuals are not born with static levels of meta-cognition but rather that it is malleable and can be developed over time (Kuhn, 2000; Paris \& Winograd, 1990; Schraw, 1998; Veenman et al., 2004). Practical methods that can be applied in a learning context or classroom setting in order to assist in the development of meta-cognition of students have been suggested. According to Schraw (1998), meta-cognition can be increased in four ways, namely promoting general awareness of the importance of metacognition, improving knowledge of cognition, improving regulation of cognition, and fostering environments that promote metacognitive awareness. According to Paris and Winograd (1990) teachers can directly promote meta-cognition by informing students about effective problem-solving strategies and discussing cognitive and motivational characteristics of thinking. Such suggestions should be utilised to develop a training intervention delivered to the candidates in the affirmative action skills development programme to enhance their levels of meta-cognition.

The third practical application has a bearing on the design and delivery of the training programme. This study identified that certain behaviour of learners (i.e., the competencies of meta-cognitive regulation and time cognitively engaged) positively influences learning performance. The training design and delivery should therefore be structured in such a manner so as to encourage learners to engage in these behaviours and thereby positively affecting learning performance. The design and delivery of the training programme as well as the manner in which consequences following from the training programme are managed will in addition impact on learning motivation. Learning motivation should be enhanced if high learning performance during evaluation is perceived to be instrumental in the achievement of high valence outcomes and if the design and delivery of the training programme facilitates the likelihood of high classroom learning performance.

\section{Future research}

It is recommended that future research should further expand the revised Van Heerden - De Goede learning potential structural model by adding additional competency potential latent variables and competencies. Interest, prior knowledge and self-esteem are suggested as additional learning competency potential latent variables and persistence as additional learning competency that should be considered for inclusion in the revised Van Heerden - De Goede learning potential structural model in future research (Van Heerden, 2013).

It is secondly be recommended that future research on learning potential should not solely focus on the competencies and competency potentials of the individual that will be participating in the skills development, but to take a more holistic stance acknowledging that the success during an affirmative action skills development intervention is not determined in isolation by the characteristics and behaviours of the learner, but that situational factors also play a role. It is therefore suggested that factors pertaining to the design and delivery of the training should be considered. Having an understanding of the design and delivery of the training and how it affects learning performance would directly empower organisations with the knowledge to develop their training programmes in such a way to most optimally encourage success during affirmative action skills development opportunities. In addition the home- and social environment of the individual should also be taken into consideration. It is implicitly expected that the home- and social environment of the affirmative action candidate will not optimal. Having an understanding of the dynamics of the home- and social environment of the individual and how if affect learning performance may ultimately allow organisations to counteract the negative effects of the homeand social environment. Formally including a latent variable like situational favourableness in the learning potential structural model will also force theorising to consider what allow learners to successfully overcome adversity in their home- and social environment. Latent variables like psychological capital (hope, optimism, resilience and selfefficacy) (Luthens, Luthens \& Luthens, 2004) and grit (Duckworth, Peterson, Matthews \& Kelly, 2007) present themselves as variables to consider for inclusion in a model that formally acknowledges the fact that for many South Africans life is harsh, brutal and unaccommodating. This line of reasoning dove-tails nicely with the earlier argument on persistence as a learning competency worthy of inclusion in the model.

\section{Limitations to this study}

The following limitations to this study should be noted. Firstly, the proposed learning potential structural model was tested on a non-probability, convenience sample of Grade 12 learners from three high schools under the Western Cape Department of Education. The three high schools were also selected on a non-probability, convenience basis. Due to the non-probability sampling procedure that was used to select the sample it cannot be claimed that the sample is representative of the target population. Furthermore to sampling limitation, due to the affirmative action perspective from which this study stems one would want to argue that the sample needs to consist of participants that qualify as affirmative development candidates. Therefore it specifically it stands out that the sample of respondents was not affirmative action candidates from disadvantages backgrounds but mostly from middle class socio-economic status. Although it was sufficiently argued that it is deemed acceptable to draw a sample that includes participants that does not qualify as affirmative development candidates, it still remains a limitation of the study that sample was not from a disadvantaged affirmative action background. Therefore, replication of this research on other samples and in different developmental contexts is therefore encouraged.

The second limitation relates to the measuring instruments used in this study. The instruments used are self-report measures. Self-report measures run the risk of social 
desirability. This, in turn, impacts on the reported levels of the constructs investigated and it influences the results (Elmes, Kantowitz \& Roediger, 2003). Exclusive reliance on self-report measures in addition also creates method bias. In the structural model that was tested the focal endogenous latent variable learning performance during evaluation was at least not obtained via self-report measures but was tested with objectively by using the results obtained on English $1^{\text {st }}$ language and Afrikaans $2^{\text {nd }}$ language during their first semester.

Vandenberg and Grelle (2009) presents a seemingly convincing argument of the importance to examine alternative model specifications (AMS) practices as applied to confirmatory factor analysis and structural equation modeling. According to Vanderberg and Grelle, AMS is seldom undertaken despite compelling arguments in support of its application. Vanderberg and Grelle describe three basic AMS strategies, namely equivalent models, nested models and nonnested alternative models. The compelling argument that Vanderberg and Grelle posits in favour of AMS alludes that third limitation of this study would be that no alternative, theoretically justifiable, models were tested.

\section{Concluding remarks}

South Africa is currently facing challenges such as a skills shortage across most industry sectors, high unemployment and poverty rates, and inequality in terms of income distribution as well as in terms of racial representation in the workforce. The country is furthermore facing social problems such as high crime rates and high incidence of HIV/AIDS. These challenges are pervasive and debilitating and negatively influence all spheres of society. Addressing the root cause of the challenges, namely the fact that Black individuals lack skills, knowledge and abilities due to the consequences of Apartheid, is essential and require urgent and collaborative attention. This study is a step, albeit a modest one, in the direction of addressing the situation. It should however be noted that it is not only important for further research to be undertaken to build upon this study and also other relevant themes, the results of these studies must be filtered through to organisations for their practical use. Too often findings of research remain locked in academic journals and remain confined to library shelves. Theoretical studies published in academic journals will in and by themselves not contribute towards solving the challenges the country is facing. Rather, it requires a collaborative relationship where academia impart the knowledge they gain from their studies to organisations in a practical manner that they will be able to apply in the way they conduct their business.

\section{References}

Alexander, N. 2006. Affirmative action and the perpetuation of racial identities in post-apartheid South Africa. University of Fort Harare: Zimbabwe.
Ames, C. \& Archer, J. 1988. 'Achievement goals in the classroom: Students' learning strategies and motivation processes'. Journal of Educational Psychology, 80(3): 260267.

Anderson, J. R. \& Reder, L. M. 1979. 'An elaborative processing explanation of depth of processing'. In Cermak, L.S. \& Craik, F. I. M. (eds.). Levels of processing in human memory. Hillsdale, NJ: Erlbaum, pp. 385-395.

Appleton, J.J., Christenson, S.L., Kim, D. \& Reschly, A.L. 2006. 'Measuring cognitive and psychological engagement: Validation of the Student Engagement Instrument', Journal of Social Psychology, 44:427-445.

Baird, G.L., Scott, W.D., Dearing, E. \& Hamill, S.K. 2009. 'Cognitive self-regulation in youth with and without learning disabilities: Academic self-efficacy, theories of intelligence, learning vs. performance goal preferences, and effort attributions', Journal of Social and Clinical Psychology, 28(7): 881-908.

Baker, L. 1989. 'Meta-cognition, comprehension monitoring, and the adult reader', Educational Psychology Review, 1: 3-38.

Bandura, A. 1977. 'Self-efficacy: Toward a unifying theory of behavioral change', Psychological Review, 84(2): 191215 .

Bandura, A. 1986. Social foundations of thought and action. Englewood Cliffs: Prentice-Hall.

Bandura, A. 1997. Self-efficacy: The exercise of control. New York: Freeman.

Bandura, A., Barbaranelli, C., Caprara, G.V. \& Pastorelli, C. 1996. 'Multifacted impact of self-efficacy beliefs on academic functioning', Child Development, 67: 1206-1222.

Barrick, M.R. \& Mount, M.K. 1991. 'The Big Five personality dimensions and job performance: A metaanalysis', Personnel Psychology, 44: 1-26.

Barrick, M.R. \& Mount, M.K. 2005. 'Yes, personality matters: Moving on to more important matters', Human Performance, 18(4): 359-372.

Bayat, S. \& Tarmizi, R.A. 2010. 'Assessing cognitive and metacognitive strategies during algebra problem solving among university students', Procedia Social and Behavioral Sciences, 8: 403-410.

Bell, B.S. \& Kozlowski, S.W.J. 2002. 'Goal-orientation and ability: Interactive effects on self-efficacy, performance and knowledge', Journal of Applied Psychology, 87: 497-505.

Bidjerano, T. \& Dai, D.Y. 2007. 'The relationship between the big-five model of personality and self-regulated learning strategies', Learning and Individual Differences, 17: 69-81. 
Boström, L. \& Lassen, L.M. 2006. 'Unraveling learning, learning styles, learning strategies, and meta-cognition', Education \& Training, 48(2): 178-189.

Brewster, C. \& Fager, J. 2000. 'Increasing student engagement and motivation: From time-on-task to homework', Northwest Regional Educational Laboratory, 14: $1-25$.

Bulus, M. 2011. 'Goal-orientations, locus of control, and academic achievement in prospective teachers: An individual differences perspective', Education Sciences: Theory \& Practice, 11(2): 540-546.

Button, S.B., Mathieu, J.E. \& Zajac, J.M. 1996. 'Goal orientation in organizational research: A conceptual and empirical foundation', Organizational Behaviour and Human Decision Processes, 67(1): 26-48.

Chapman, E. 2003. 'Alternative approaches to assessing student engagement rates', Practical Assessment, Research \& Evaluation, 4(9): 1-7.

Chen, G., Gully, S. M. \& Eden, D. 2001. 'Validation of a new general self-efficacy scale', Organisational Research Methods, 4: 62-83.

Chiaburu, D.S. \& Marinova, S.V. 2005. 'What predicts skill transfer? An exploratory study of goal-orientation, training self-efficacy and organizational supports', International Journal of Training and Development, 9(2): 110-123.

Colquitt, J.A. \& Simmering, M.J. 1998. 'Conscientiousness, goal-orientation, and motivation to learn during the learning process: A longitudinal study', Journal of Applied Psychology, 83(4): 654-665.

Colquitt, J.A., LePine, J.A. \& Noe, R.A. 2000. 'Toward an integrative theory of training motivation: A meta-analytic path analysis of 20 years of research', Journal of Applied Psychology, 85(5): 678-707.

Craik, F. I. M. \& Lockhart, R. S. 1972. 'Levels of processing: A framework for memory research', Journal of Verbal Learning and Verbal Behavior, 11: 671-684.

Davis, H.A., Chang, M., Andrzejewski, C.E. \& Poirier, R.R. 2010. 'Examining behavioral, relational, and cognitive engagement in smaller learning communities: A case study of reform in one suburban district',Journal of Educational Change, 11: 345-401

Day, E., Yeo, S. \& Radosevich, D. J. 2003. 'Comparing two- and three-factor models of goal orientation: A metaanalysis.' Paper presented at the 18th Annual Society for Industrial and Organizational Psychology Convention, Orlando, Florida 13 April.

De Goede, J. 2007. 'An investigation into the internal structure of the learning potential construct as measured by the APIL test battery'. Unpublished master's thesis, University of Stellenbosch.

De Goede, J. \& Theron, C.C. 2010. 'An investigation into the internal structure of the learning potential construct as measured by the APIL-B test battery', Management Dynamics, 19(4): 30-55.

Dean, M.A., Conte, J.M. \& Blankenhorn, T.R. 2006. 'Examination of the predictive validity of Big Five personality dimensions across training performance criteria', Personality and Individual Differences, 41: 1229-1239.

Department of Labour. nd. 'Chapter Three: Framework for managing HIV/AIDS in the workplace'. In HIV/AIDS technical assistance guidelines. Pretoria: Department of Labour, pp.39-74.

Department of Higher Education and Training. 2010. Framework for the National Skills Development Strategy. Consultative Document, April 2010. Pretoria: Department of Higher Education and Training

Diamantopoulos, A. \& Siguaw, J.A. 2000. Introducing LISREL. London: SAGE Publications, Inc.

Du Toit, S. \& Du Toit, M. 2001. Interactive LISREL: User's Guide. Illinois: Scientific Software International.

Duckworth, A.L., Peterson, C., Matthews, M.D. \& Kelly, D.R. 2007. 'Grit: Perseverance and passion for long-term goals', Journal of Personality and Social Psychology, 92(6): 1087-1101.

Dupeyrat, C. \& Marine, C. 2005. 'Implicit theories of intelligence, goal orientation, cognitive engagement, and achievement: A test of Dweck's model with returning to school adults', Contemporary Educational Psychology, 30: 43-59.

Dweck, C.S. \& Leggett, E.L. 1988. 'A social-cognitive approach to motivation and personality', Psychological Review, 95(2):256-273.

Efklides, A. 2006. 'Metacognition and affect: What can metacognitive experiences tell us about the learning process?' Educational Research Review, 1: 3-14.

Eilam, B., Zeidner, M. \& Aharon, I. 2009. 'Student conscientiousness, self-regulated learning, and science achievement: An explorative field study', Psychology in the Schools, 46(5): 420-432.

Elmes, D.G., Kantowitz, B.H. \& Roediger, H.L. 2003. Research methods in psychology ( $7^{\text {th }}$ Edition). Belmont, CA: Wadsworth/Thompson.

Farr, J. L., Hofmann, D. A. \& Ringenbach, K. L. 1993. 'Goal orientation and action control theory: Implications for industrial and organizational psychology'. In Cooper, C. L. \& Robertson, I. T. (eds.). International review of industrial 
and organizational psychology. New York: Wiley, pp. 193232.

Flavell, J.H. 1976. 'Metacognitive aspects of problem solving'. In Resnick, L.B. (ed.). The nature of intelligence. Hillsdale, NJ: Erlbaum, pp. 231-235.

Ford, J.K., Smith, E.M., Weissbein, D.A., Gully, S.M. \& Salas, E. 1998. 'Relationship of goal-orientation, metacognitive activity, and practice strategies with learning outcomes and transfer', Journal of Applied Psychology, 83(2): 218-233.

Freeman, J. 2005. 'Mdladlana proposes FET college takeover. Skills $\quad$ Portal.' [online] URL:http://www.skillsportal.co.za/page/skills-

development/468807-Mdladlana-proposes-FET-college-

takeover .Accessed 18 May, 2011.

Furnham, A., Monsen, J. \& Ahmetoglu, G. 2009. 'Typical intellectual engagement, Big Five personality traits, approaches to learning and cognitive ability predictors of academic performance', British Journal of Educational Psychology, 79: 769-782.

Georghiades, P. 2004. 'From the general to the situated: three decades of metacognition', International Journal of Science and Education, 26(3): 365 - 383.

Gettinger, M. \& Seibert, J.K. 2006. 'Best practices in increasing academic learning time', Best Practices in School Psychology, 5: 1-15.

Gibson, J.L., Ivancevich, J.M., Donnelly, J.H. \& Konopaske, R. 2006. Organizations: Behavior, structure, processes. New York: McGraw-Hill.

Greene, B.A. \& Miller, R.B. 1996. 'Influences on achievement: Goals, perceived ability, and cognitive engagement', Contemporary Educational Psychology, 21: 181-192.

Greene, B.A., Miller, R.B., Crowson, H.M., Duke, B.L. \& Akey, K.L. 2004. 'Predicting high school students cognitive engagement and achievement: Contributions of classroom perceptions and motivation', Contemporary Educational Psychology, 29: 462-482.

Hair, J.F., Black, W.C., Babin, B.J., Anderson, R.E. \& Tatham, R.L. 2006. Multivariate data analysis ( $6^{\text {th }}$ Edition). Upper Saddle River, NJ: Pearson Education Inc.

Hsieh, P., Sullivan, J.R. \& Guerra, N.S. 2007. 'A closer look at college students: Self-efficacy and goal orientation', Journal of Advanced Academics, 18(3): 454-476.

'International Personality Item Pool'. 2001. [online]URL:http://ipip.ori.org/newNEOKey.htm\#Conscient iousness. Accessed 14 June 2012.
Joo, Y.J., Joung, S. \& Sim, W.J. 2011. 'Structural relationships among internal locus of control, institutional support, flow, and learner persistence in cyber universities', Computers in Human Behavior, 27: 714-722.

Jöreskog, K.G. \& Sörbom, D. 1998. Structural equation modelling with the SIMPLIS command language. Chicago: Scientific Software International

Judge, T. A., Erez, A., Bono, J. E. \& Thoresen, C. J. 2002. 'Are measures of self-esteem, neuroticism, locus of control, and generalized self-efficacy indicators of a common core construct?' Journal of Personality and Social Psychology, 83: 693-710.

Judge, T.A. \& Bono, J.E. 2001. 'Relationship of core selfevaluation traits - self-esteem, generalized self-efficacy, locus of control, and emotional stability - with job satisfaction and job performance: A meta-analysis', Journal of Applied Psychology, 86(1): 80-92.

Kanfer, R. 1991. 'Motivation theory and industrial/organisational psychology', Handbook of Industrial and Organisational Psychology, 1: 75-170.

Kanfer, R. \& Heggestad, E. 1997. 'Motivational traits and skills: A person-centered approach to work motivation' In Cummings, L. L. \& Staw, B. M. (eds.). Research in Organizational Behavior, 19:1-57.

Kelloway, E.K. 1998. Using LISREL for structural equation modelling: A researcher'guide. Thousand Oaks, CA: SAGE Publications, Inc.

Kozlowski, S.W., Gully, S.M., Brown. K.G., Salas, E., Smith, E.M. \& Nason, E.R. 2001. 'Effects of training goals and goal orientation traits on multidimensional training outcomes and performance adaptability', Organizational Behaviour and Human Decision Processes, 85(1): 1-31.

Krapp, A. 1999. 'Interest, motivation, and learning: an educational-psychological perspective', European Journal of Psychology of Education, 14(1): 23-40.

Kuhn, D. 2000. 'Metacognitive development', Current Directions in Psychological Science, 9(5): 178-181.

Landine, J. \& Stewart, J. 1998. 'Relationship between metacognition, motivation, locus of control, self-efficacy, and academic achievement', Canadian Journal of Counselling, 32(3): 200-212.

Letsoalo, M. 2007a. 'Seta results a big blow for government'. Mail and Guardian. [online]URL: http://mg.co.za/article/2007-10-31-seta-results-a-big-blowfor-government. Accessed 18 May 2011.

Letsoalo, M. 2007b. 'Mismanagement of funds plagues many of SA's Setas.' Mail and Guardian. [online]URL: http://mg.co.za/article/2007-04-24-mismanagement-offunds-plagues-many-sas-setas. Accessed 18 May 2011. 
Levenson, H. \& Miller, J. 1976. 'Multidimensional locus of control in sociopolitical activists of conservative and liberal ideologies', Journal of Personality and Social Psychology, 33: $199-208$.

Liem, A.D., Lau, S. \& Nie, Y. 2008. 'The role of selfefficacy, task value, and achievement goals in predicting learning strategies, task disengagement, peer relationship, and achievement outcome', Contemporary Educational Psychology, 33: 486-512.

Little, T.D., Cunningham, W.A. \& Shahar, G. 2002. 'To parcel or not too parcel: Exploring the question, weighing the merits', Structural Equation Modeling, 9(2): 151-173.

Locke, E. 1996. 'Motivation through conscious goalsetting', Applied \& Preventive Psychology, 5: 117-124.

Luthens, F. Luthens, K.W. \& Luthens, B.C. 2004. 'Positive psychological capital: Beyond human and social capital', Business Horizons, 47(1), 45-50.

Marks, L.I. 1998. 'Deconstructing locus of control: Implications for practitioners', Journal of Counseling \& Development, 76: 251- 260.

McCrae, R. R. \& Costa, P. T. 1999. 'A five-factor theory of personality'. In Pervin, L.A. \& John, O.P. (eds.). Handbook of personality. New York: Guilford, pp. 139-153.

McKenzie, K., Gow, K. \& Schweitzer, R. 2004. 'Exploring first-year academic achievement through structural equation modelling', Higher Education Research and Development, 23(1): 95-112.

McWhaw, K. \& Abrami, P.C. 2001. 'Student goalorientation and interest: effects in students' use of selfregulated learning strategies', Contemporary Educational Psychology, 26: 311-329.

Mels, G. 2003. A workshop on structural equation modelling with LISREL 8.54 for Windows. Chicago, IL: Scientific Software International.

Mels, G. 2010. Structural equation modelling with LISREL 9 for Windows. Chicago: Scientific Software International.

Metallidou, P. \& Vlachou, A. 2007.'Motivational beliefs, cognitive engagement, and achievement in language and mathematics in elementary school children', International Journal of Psychology, 42(1): 2-15.

Mitchell, J.R., Smith, J.B., Gustafsson, V., Davidsson, P. \& Mitchell, R.K. 2005. 'Thinking about thinking about thinking.' Paper presented at the Babson Research Conference, Massachusetts, USA 10 June.

National Student Financial Aid Scheme (NSFAS). 2010. National Student Financial Aid Scheme Annual Report 2010. South Africa:NSFAS.
Ncana, N. 2010. 'Blade orders skills growth'. Times Live. [online]URL:http://www.timeslive.co.za/sundaytimes/article 264346.ece. Accessed 20 January 2011.

Nijhuis, J., Segers, M. \& Gijselaers, W. 2007. 'The interplay of perceptions of the learning environment, personality and learning strategies: a study amongst International Business Studies students', Studies in Higher Education, 32(1): 5977.

Nonis, S.A. \& Hudson, G.I. 2006. 'Academic performance of college students: Influence of time spent studying and working', Journal of Education for Business, January/February:151-159.

Nunes, C. 2003. 'The effects of trainee ability and motivation on the transfer process'. Unpublished master's thesis. University of Stellenbosch.

Nunnally, J.C. 1978. Psychometric theory. (2 ${ }^{\text {nd }}$ Edition). New York: McGraw-Hill.

O'Connor, M.C. \& Paunonen, S.V. 2007. 'Big five personality predictors of post-secondary academic performance', Personality and Individual Differences, 43: 971-990.

Paris, S.G. \& Winograd, P. 1990. 'Promoting metacognition and motivation of exceptional children', Remedial and Special Education, 11(6): 7-15.

Payne, S.C., Youngcourt, S.S. \& Beaubien, J.M. 2007. 'A meta-analytic examination of the goal orientation nomological net', Journal of Applied Psychology, 92(1): 128-150.

Phan, H.P. 2010. 'Students' academic performance and various cognitive processes of learning: An integrative framework and empirical analysis', Educational Psychology, 30(3): 297-322.

Pintrich, P. R. \& Schrauben, B. 1992. 'Students' motivational beliefs and their cognitive engagement in classroom academic tasks'. In Schunk, D.H. \& Meece, J.L. (eds.). Student perceptions in the classroom. Hillsdale, NJ: Erlbaum, pp. 149-183.

Rastegar, A., Jahromi, R.G., Haghigli, A.S. \& Akbari, A.R. 2010. 'The relation of epistemological beliefs and mathematics achievement: The mediating role of achievement goals, mathematics self-efficacy, and cognitive engagement', Procedia Social and Behavioural Sciences, 5: 791-797.

Ravindran, B., Greene, B.A. \& DeBacker, T.K. 2005. 'Predicting preservice teachers' cognitive engagement with goals and epistemological beliefs', The Journal of Educational Research, 98(4): 222-232.

Republic of South Africa. 1998. 'Employment Equity Act', Government Gazette, No. 19370, 19 October 1998. 
Richardson, J.C. \& Newby, T. 2006. 'The role of students' cognitive engagement in online learning', The American Journal of Distance Education, 20(1): 23-37

Salas, E. \& Cannon-Bowers, J.A. 2001. 'The science of training: A decade of progress', Annual Reviews Psychology 52: 471-499.

Schmidt, A.M. \& Ford, K. 2003. 'Learning within a learner control training environment: The interactive effect of goalorientation and meta-cognitive instruction on learning outcomes', Personnel Psychology, 56: 405-429.

Schmitt, M.C. \& Sha, S. 2009. 'The developmental nature of meta-cognition and the relationship between knowledge and control over time', Journal of Research in Reading, 32(2): 254-271.

Schraw, G. \& Dennison, R.S. 1994. 'Assessing metacognitive awareness', Contemporary Educational Psychology, 19:460-475.

Schraw, G. 1998. 'Promoting general metacognitive awareness', Instructional Science, 26: 113-125.

Schunk, D. H. 1990.'Goal setting and self-efficacy during self-regulated learning', Educational Psychologist, 25: 7186.

Schwartz, B.L. \& Perfect, T.J. 2002 'Introduction: toward an applied meta-cognition'. In Perfect, T.J. \& Schwartz, B.L. (eds.). Applied meta-cognition. Cambridge: Cambridge University Press, pp. 1-9.

Sedaghat, M., Abedin, A., Hejazi, E. \& Hassanabadi, H. 2011. 'Motivation, cognitive engagement, and academic achievement', Procedia Social and Behavioral Sciences, 15: 2406-2410.

Singh, K., Granville, M. \& Dika, S. 2002.'Mathematics and science achievement: Effects of motivation, interest, and academic engagemen,' The Journal of Educational Research, 95(6): 323-332.

Sins, P.H.M, Van Joolingen, W.R., Savelsbergh, E.R. \& Van Hout-Wolters, B. 2008. 'Motivation and performance within a collaborative computer-based modeling task: Relations between students' achievement goal orientation, self-efficacy, cognitive processing, and achievement', Contemporary Educational Psychology, 33: 58-77.

Skinner, E., Marchand, G., Furrer, C. \& Kindermann, T. 2008. 'Engagement and disaffection in the classroom: Part of a larger motivational dynamic?' Journal of Educational Psychology, 100(4): 765-781.

Sperling, R.A., Howard, B.C., \& Staley, H. 2004. 'Metacognition and self-regulated learning constructs', Educational Research and Evaluation, 10(2): 117 - 139.
SPSS. 2011. 'IBM SPSS statistics'. [online]URL: http://www01.ibm.com/software/analytics/spss/products/stat istics/. Accessed 28 October 2011.

Steinmayr, R., Bipp, T. \& Spinath, B. 2011. 'Goal orientations predict academic performance beyond intelligence and personality', Learning and Individual Differences, 21: 196-200.

Stokes, G. 2009. 'Had enough of the employment equity debate?' FAnews [online] URL:http://www.fanews.co.za/ article.asp? Front_Page_Features;25,Stokes_Stage;1145, Had_enough_of_the employment_equity_debate; 6766 . Accessed 19 May 2011.

Sunday Times, 9/1/2011. ' Tackling SA's skills shortage. [online]URL: http://www.dinokengscenarios.co.za/s cen_2.php 22 march 2013. Accessed 23 March 2013.

Tabachnick, B.G. \& Fidell, L.S. 2001. Using multivariate statistics. ( $4^{\text {th }}$ Edition.). Needham Heights, MA: Allyn \& Bacon.

Taylor, T.R. 1989. 'International developments in psychological assessment'. Paper presented at the Congress on Psychometrics for Psychologists. Megawatt Park, Sandton: Eskom and the Institute of Industrial Psychology of South Africa. 8-9 June 1989.

Taylor, T.R. 1992. 'Beyond competence: Measuring potential in a cross-cultural situation fairly: potential in psychometrics' Part 2. Paper presented at the Congress on Psychometrics for Psychologists. Megawatt Park, Sandton: Eskom and the Society of Industrial Psychology of South Africa. 10-12 June 1992.

Taylor, T.R. 1994. 'A review of three approaches to cognitive assessment, and proposed integrated approach based on a unifying theoretical framework', South African Journal of Psychology, 24(4): 184-193.

Taylor, T.R. 1997. Administrator's manual for APIL-B BATTERY. Auckland Park: AProLAB.

Teffo, J. 2008. Education for poverty alleviations: Myth or Reality? In Maile S. (ed.). Education and poverty reduction strategies. Cape Town: HSRC Press, pp. 53-67.

Tobias, S. \& Everson, H.T. 1996. 'Assessing metacognitive knowledge monitoring', College Board Report, 96(1): 1-31.

Turban, D. B., Stevens, C. K. \& Lee, F. 2009. 'Effects of conscientiousness and extraversion on new labor market entrants' job search: The mediating role of meta-cognitive activities and positive emotions', Personnel Psychology, 63: 553-573.

Van Heerden. S. 2013. 'Elaboration and empirical evaluation of the De Goede learning potential structural model', Unpublished master's thesis, University of Stellenbosch. 
Van Hooft, E.A.J. \& Noordzij, G. 2009. 'The effects of goal orientation on job search and reemployment: A field experiment among unemployed job seekers', Journal of Applied Psychology, 94(6): 1581-1590.

Vandenberg, R.J. \& Grelle, D.M. 2009. 'Alternative model specifications in structural equation modeling: Facts, fictions, and truth.' In Lance, C.E. \& Vandenberg, R.J (eds.). Statistical and methodological myths and urban legends: Doctrine, verity and fable in the organizational and social sciences. New York: Routledge, pp. 165-191.

VandeWalle, D. 1997. 'Development and validation of a work domain goal orientation instrument', Educational and Psychological Measurement, 57, 995-1015.

Veenman, M. V. J. \& Verheij, J. 2003. 'Identifying technical students at risk: Relating general versus specific meta-cognitive skills to study success', Learning and Individual Differences, 13:259-272.

Veenman, M. V. J., Elshout, J. J. \& Meijer, J. 1997. 'The generality vs. domain-specificity of meta-cognitive skills in novice learning across domains', Learning and Instruction, 7: 187-209.

Veenman, M. V. J., Wilhelm, P. \& Beishuizen, J. J. 2004. 'The relation between intellectual and meta-cognitive skills from a developmental perspective', Learning and Instruction, 14: 89-109.

Veenman, M.V.J., Van Hout-Wolters, B.H.A.M. \& Afflerbach, P. 2006. 'Metacognition and learning: conceptual and methodological considerations', Metacognition Learning, 1: 3-14.

Wang, Q., Bowling, N.A. \& Eschleman, K.J. 2010. 'A metaanalytic examination of work and general locus of control', Journal of Applied Psychology, 95(4): 761-768.

Wang, Y., Peng, H., Huang, R., Hou, Y. \& Wang, J. 2008. 'Characteristics of distance learners: Research on relationships of learning motivation, learning strategy, selfefficacy, attribution and learning results' Open Learning, 23(1): 17-28.

Woo, S.E., Harms, P.D. \& Kuncel, N.R. 2007. 'Integrating personality and intelligence: Typical intellectual engagement and need for cognition', Personality and Individual Differences, 43: 1635-1639.

Woolard, I. \& Leibbrandt, M. 1999. 'Measuring poverty in South Africa'. Development Policy Research Unit. University of Cape Town.

World Economic Forum. 2009. The Global Competitiveness Report 2009-2010. [online]URL:http://www.weforum.org/ documents/GCR09/index.html . Accessed 15 August 2010.
Zhu, X., Chen, A., Ennis, C., Sun, H., Hopple, C., Bonello, M., Bae, M. \& Kim, S. 2009. 'Situational interest, cognitive engagement, and achievement in physical education.', Contemporary Educational Psychology, 34: 221-229.

Zimmerman, B.J. 2000. 'Self-efficacy: An essential motive to learn', Contemporary Educational Psychology, 25: 8291. 